\title{
EL SECTOR DEL TRANSPORTE EN LEÓN. INFRAESTRUCTURAS Y SERVICIOS
}

\author{
Cristina Álvarez Folgueras \\ Área de Economía Aplicada \\ Departamento de Economía y Estadística \\ Universidad de León \\ e-mail: cristina.afolgueras@unileon.es
}

1. Introducción: El transporte en nuestra sociedad - 2. Las infraestructuras de transporte en León: 2.1. Infraestructuras viarias: 2.1.1. Red de carreteras del Estado, 2.1.2. Red de carreteras de la Comunidad Autónoma, 2.1.3. Red de carreteras de la Diputación de León, 2.1.4. Estaciones de autobuses; 2.2.Infraestructuras ferroviarias, 2.3. Infraestructuras aéreas, 2.4. Puertos, 2.5. El modelo CyLoG - 3. Los servicios de transporte en León: 3.1.Transporte de mercancías: 3.1.1. Por carretera, 3.1.2. Ferroviario y aéreo; 3.2. Transporte interurbano de viajeros: 3.2.1. Por carretera, 3.2.2. Ferroviario y aéreo - 4. Conclusiones - Referencias

\section{Introduc ción: $\theta$ transporte en nuestra sociedad}

El transporte es una actividad esencial en cualquier sociedad, tanto desde el punto de vista de la oferta, al ser uno de los principales componentes del sector servicios como desde el punto de vista de la demanda, al ser cada vez más necesario en las actividades laborales o de ocio de la ciudadanía.

La facilidad para mover mercancías entre las distintas partes del territorio, o hacia el interior y hacia el exterior de este, es uno de los ejes centrales para que el sistema productivo funcione eficientemente, por lo que el transporte se ha convertido en elemento crucial de las decisiones sobre localización empresarial. Por otro lado, el transporte, y más específicamente un sistema de transporte público eficaz y adecuado, contribuye a satisfacer las necesidades de movilidad de los ciudadanos para acceder al lugar de estudio u ocio, favoreciendo así a la mejora del bienestar de la sociedad.
Por ellos, ya es habitual considerar a las infraestructuras que permiten el uso del material móvil (camiones, ferrocarriles, etc.) como un factor similar al conocimiento, el trabajo o el capital privado. Y además, su construcción va acompañada de un aumento de la demanda de factores de producción, especialmente en el territorio en el que se está construyendo, lo que impacta muy positiva y rápidamente en los niveles de crecimiento.

En consecuencia, el transporte se ha convertido en fundamental para el desarrollo económico y social de las comunidades, la vertebración del territorio y la integración y cohesión del espacio. La política de infraestructuras de transporte y todo lo relacionado con su planificación, ejecución y explotación es ya elemento esencial de la política económica de cualquier gobierno, tanto local como regional o nacional.

En términos cuantitativos y aun reconociendo lo simplista de la medida, en una sociedad desarrollada, el valor añadido generado por el sector del transporte oscila, de forma más o 
menos cíclica, entre el 3\% y el 5\% del PNB, la inversión pública a él asociada representa entre el $2 \%$ y el $2,5 \%$ del PNB y absorbe entre el $5 \%$ y el $8 \%$ del total del empleo asalariado, y sus efectos indirectos pueden más que duplicar los directos.

Pero también el transporte es responsable de gran cantidad de impactos sociales y ambientales negativos, como por ejemplo la contaminación atmosférica, el ruido, los accidentes, la pérdida de biodiversidad por la fragmentación de los hábitat, la congestión o la dependencia energética.

En cuanto a modos de transporte, en España, al igual que en toda Europa, y precisamente de forma más acusada desde su adhesión a la Unión Europea, la carretera es el modo que ha experimentado un mayor crecimiento, pues se han pasado de transportar así el 24\% del total de mercancías y el 39\% de los viajeros en 1950 a transportar el $83 \%$ de las mercancías y el $90,8 \%$ de los viajeros en 2009 , casi todos ellos utilizando automóviles particulares (véanse
Gráficos 1 y 2). En contrapartida, ha disminuido la importancia del ferrocarril, que apenas mueve el $2 \%$ de la mercancía transportada y el 5,2\% de los viajeros, a pesar del repunte positivo en aquellos corredores donde se ha instaurado la Alta Velocidad.

Esta polarización modal tiene diversas implicaciones negativas de importancia, como la creciente densidad de red de carreteras, la tendencia a la congestión en los ejes principales, la contaminación ambiental, el descenso de los niveles de calidad ofrecida a los usuarios o la elevada siniestralidad.

En relación a la densidad, a pesar de que León es la provincia de la Comunidad Autónoma con mayor superficie (16\%), más población (20\%), mayor número de kilómetros de carreteras $(18,4 \%$ del total; $33,4 \%$ de las autopistas, y $26,3 \%$ de las de doble calzada) y mayor parque de vehículos pesados $(21,3 \%)$, no muestra la mayor concentración de tráfico de la Comunidad Autónoma ni presenta puntos de importante congestión en las vías no urbanas.

\section{Gráfico 1}

\section{Evolución del reparto modal del tráfico interior de viajeros en España}

1950

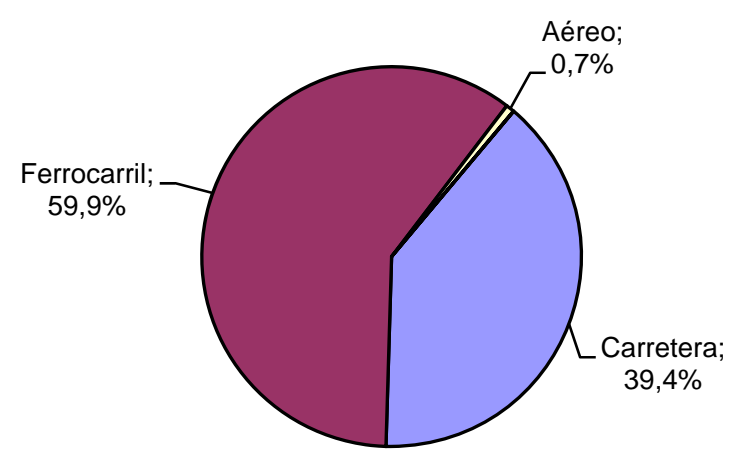

2009

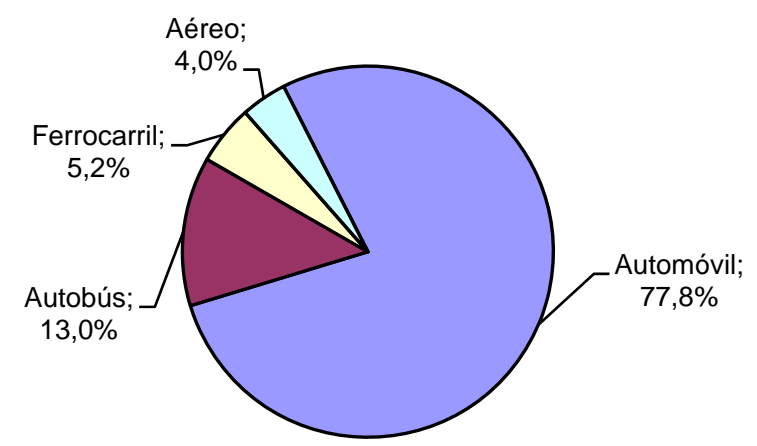

Fuente: Ministerio de Fomento. Observatorio del Transporte de Viajeros (2008 y 2012). 


\section{Gráfico 2}

\section{Evolución del reparto modal del tráfico interior de mercancías en España}
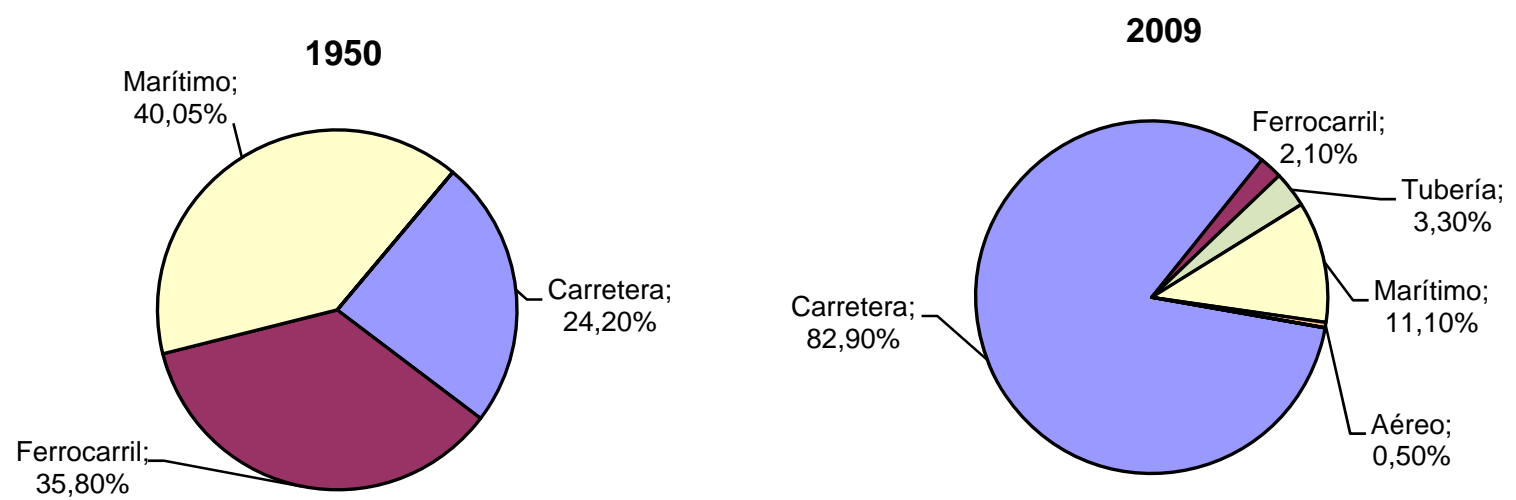

Fuente: Ministerio de Fomento. Observatorio del Transporte de Mercancías (2008 y 2012).

Mucho peores son los impactos medioambientales. El aumento de la utilización de la carretera y en menor medida, del transporte aéreo, ha sido la causa fundamental del aumento de las emisiones de gases de efecto invernadero en actividades de combustión por parte del sector. Por ejemplo, en Castilla y León el Transporte por carretera supone más del $15,33 \%$ de las emisiones totales de la Comunidad Autónoma, peso relativo que se ha ido incrementando de manera casi continua. Según el Informe Aplicación del Protocolo de Kyoto para Castilla y León, publicado por el Consejo Económico y Social de Castilla y León en 2006, los vehículos de carga y autobuses son responsables de más del $56 \%$ de estas emisiones y el $13 \%$ de las mismas corresponde al parque móvil leonés de este tipo de vehículos ${ }^{1}$.

La carretera también es la responsable y principal protagonista de una de las grandes preocupaciones de la sociedad actual en relación al transporte: la elevada siniestralidad. En las carreteras de la provincia de León se producen alrededor de 800 accidentes con víctimas al año (véase Gráfico 3), aunque con una tendencia claramente decreciente durante

\footnotetext{
1 Aunque es sabido que la crisis económica ha reducido los niveles de emisiones, aún no existe estudio sistemático que evalúe los niveles con posterioridad a 2005.
}

la última década. En 2012, estos accidentes han supuesto el $18,6 \%$ de los producidos en Castilla y León y menos del $1 \%$ del total nacional.

Las cuestiones medioambientales y de siniestralidad son de tal calado que las nuevas políticas públicas sectoriales están centradas en el aumento de la intermodalidad y en la internalización de los costes externos generados por el transporte (polución, congestión, accidentalidad, etc.), considerados por algunos autores casi tan importantes como la aportación que el sector realiza al desarrollo y a la generación de riqueza. De tal manera, la estrategia europea en esta materia (Comisión de las Comunidades Europeas, 2001) que en gran medida y de forma creciente determina las actuaciones públicas en la provincia de León, tiene como objetivo principal la desconexión progresiva del crecimiento del transporte (y específicamente del transporte por carretera) del crecimiento económico, mediante un reequilibrio de los modos de transporte (revitalizando los alternativos a la carretera), la supresión de los puntos de estrangulamiento y el diseño de una política sectorial enfocada al aumento de la seguridad y la calidad. 
Gráfico 3

Accidentes con víctimas en la provincia de León (1986-2012)

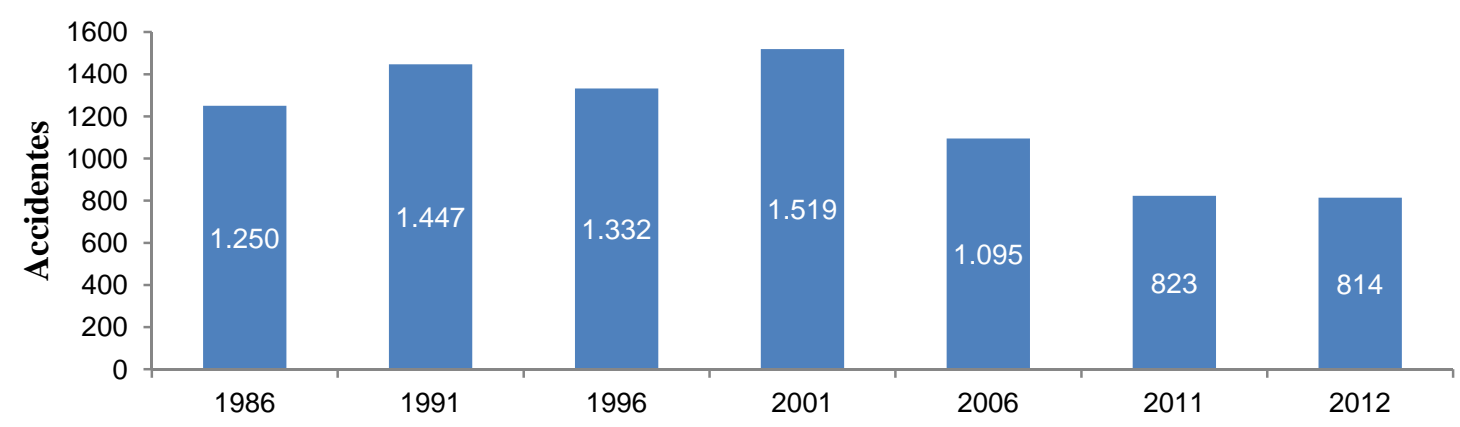

Fuente: DGT: Anuario Estadístico. Varios años.

\section{Las infraestruc turas de transporte en León}

Por las tendencias a las que hemos aludido al principio del capítulo, profundizadas por las particulares características de nuestro territorio, las inversiones en infraestructuras en la provincia de León han estado centradas en las últimas décadas en el desarrollo de la red de carreteras y en el ferrocarril de Alta Velocidad, con escasas inversiones (o incluso desinversiones) en las líneas ferroviarias convencionales.

Además, han sido especialmente importantes las inversiones para mejorar los grandes corredores de relación con la capital del país o con otras capitales de provincia, mientras la red secundaria de carreteras $y$, sobre todo, las líneas ferroviarias intraprovinciales no han sido capaces de seguir el ritmo de crecimiento necesario para ofrecer a la ciudadanía servicios de calidad suficiente a un precio aceptable. El resultado de esta concentración de inversiones en un número reducido de vías que se comportan como las partes más importantes del sistema, es que tanto la compleja red de carreteras como la red ferroviaria presentan una jerarquización elevada. Y las inversiones previstas en el futuro, aunque sujetas a la escasez presupuestaria, seguirán profundizando esta jerarquización, pues se continúa priorizando, sobre todo, la red ferroviaria de alta velocidad.

Desde el punto de vista territorial, quizá la principal cualidad o característica de las carreteras es su elevada capilaridad (Seguí y Martínez, 2003: 224), lo cual alude a la gran difusión y protagonismo de esta infraestructura en el territorio y a su disponibilidad prácticamente ilimitada de acceso, lo que genera un efecto de tipo corredor en torno a ellas. Por eso, en la provincia de León, las carreteras, principalmente las nacionales (algunas convertidas en vías rápidas), son el principal elemento vertebrador del territorio, y a lo largo de su trazado se localizan los ejes de dinamismo económico (bien sean espacios emergentes o supervivientes de desarrollo) y es donde destaca la actividad de procedencia extrarregional, ya que el territorio leonés sirve de nexo esencial de conexión entre las regiones del Norte de España, con el Centro, el Sur y el Este del país.

En cuanto a la distribución de responsabilidades por niveles de Administración, el Estado posee la competencia sobre las comunicaciones y obras públicas que afecten a más de una Comunidad Autónoma ${ }^{2}$, por lo que los sucesivos Planes de Infraestructuras nacionales, en sus variadas denominaciones específicas ${ }^{3}$, han sido de vital importancia para el diseño y desarrollo de las vías leonesas de primer nivel (ferroviarias,

2 Título VIII de la Constitución Española (art. 149.1.21 y 149.1.24).

3 Plan General de Carreteras (1985), Plan Director de Infraestructuras (1993), Plan de Infraestructuras del Transporte 2000-2007, Plan Estratégico de Infraestructuras y Transporte 2005-2020 (PEIT) y Plan de Infraestructuras, Transporte y Vivienda (PITVI 20122024). 
aéreas y de carreteras de doble vía). Las administraciones regionales y locales han tenido, básicamente, competencias en el terreno de las carreteras (nacionales, provinciales...).

Los Planes de Infraestructuras en gran medida reflejan las líneas de ayuda negociadas dentro de los diversos Programas Operativos cofinanciados por el FEDER, que han contribuido a la mejora de los indicadores de la región, aunque, según reconocía el Consejo Económico y Social de la Comunidad en 2008, "las infraestructuras de Castilla y León se encuentran por debajo de la media europea y de la media nacional. $Y$ alcanzar el nivel del entorno se ha vuelto ciertamente más duro, pues durante el período de programación 2007-2013, se seguirán cofinanciando este tipo de inversiones, aunque en menor medida que hasta ahora, y serán las infraestructuras en Investigación y Desarrollo Tecnológico las que recibirán mayor cofinanciación". Ni las siguientes Perspectivas Financieras de la Comunidad Europea, que priman las políticas de fomento del empleo, ni el escenario particular de la provincia leonesa, hacen pensar que la situación de León sea nada mejor que la expuesta por el Consejo Económico y Social para la Comunidad Autónoma en su conjunto.

\subsection{Infraestructuras viarias}

Como ya hemos dicho, en el modelo de transporte europeo, la red de carreteras ocupa la posición más importante dentro del sistema de transporte y así es, también, en la provincia de León, donde la red de carreteras en 2011 estaba constituida por 6.011 kilómetros de vía, de los cuales $919 \mathrm{~km}$ son competencia del Estado, $1.782 \mathrm{~km}$ de la Comunidad Autónoma y el resto $(3.310 \mathrm{~km})$ de la Diputación de León ${ }^{4}$.

\footnotetext{
4 Las Comunidades Autónomas tienen la competencia sobre las carreteras nacionales y las denominadas provinciales (o comarcales), aunque la gestión de estas últimas está transferida a las diputaciones, que generalmente sólo realizan actuaciones en materia de mantenimiento de la red y por norma general no ejecutan nuevas actuaciones ni modificaciones de trazado.
}

En los Gráficos 4 y 5 se observa cuál ha sido la evolución de la red de carreteras durante los últimos 25 años. El resultado es la red provincial más extensa de toda la Comunicad de Castilla y León, como corresponde a su superficie y al número de núcleos de población que existen en la provincia.

\section{Gráfico 4}

Evolución de la red de carreteras de León según la anchura del pavimento (1986-2011)
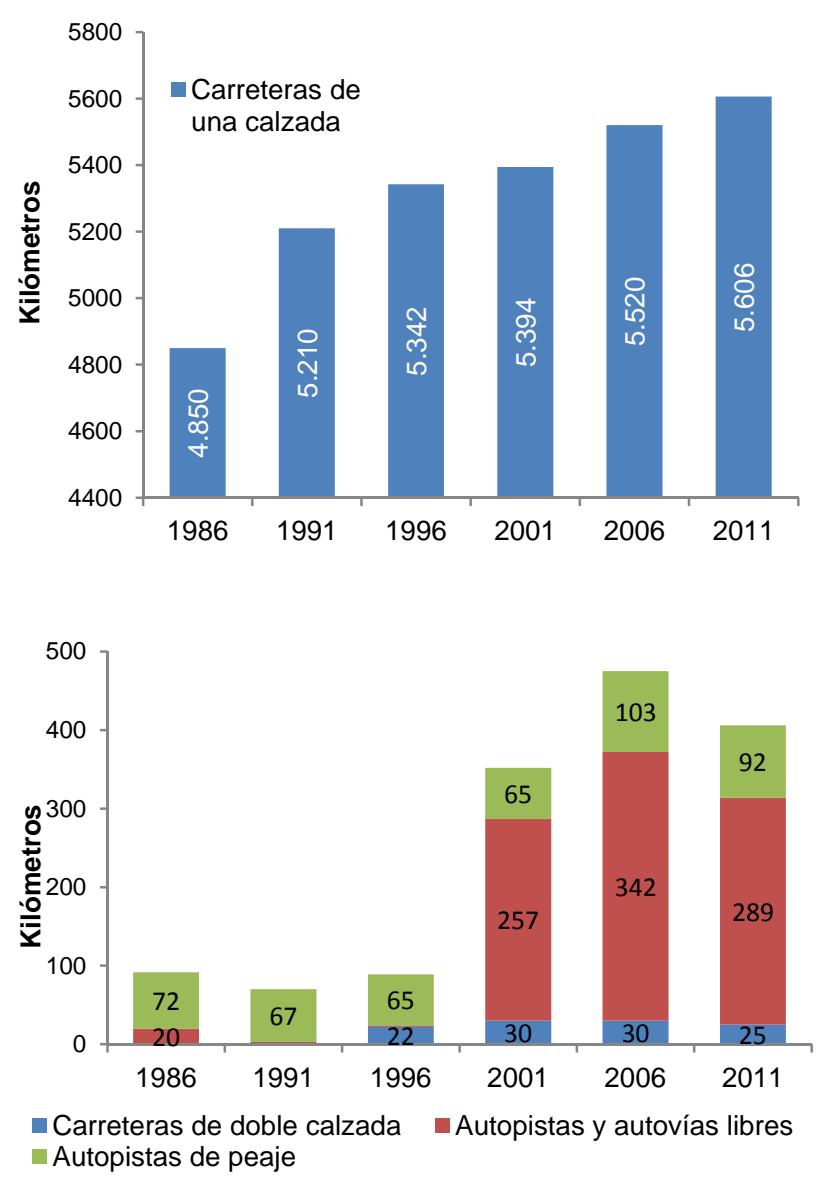

Fuente: Anuario Estadístico de Castilla y León. Varios años. 


\section{Gráfico 5}

Evolución de la red de carreteras de León según su titularidad (1986-2011)

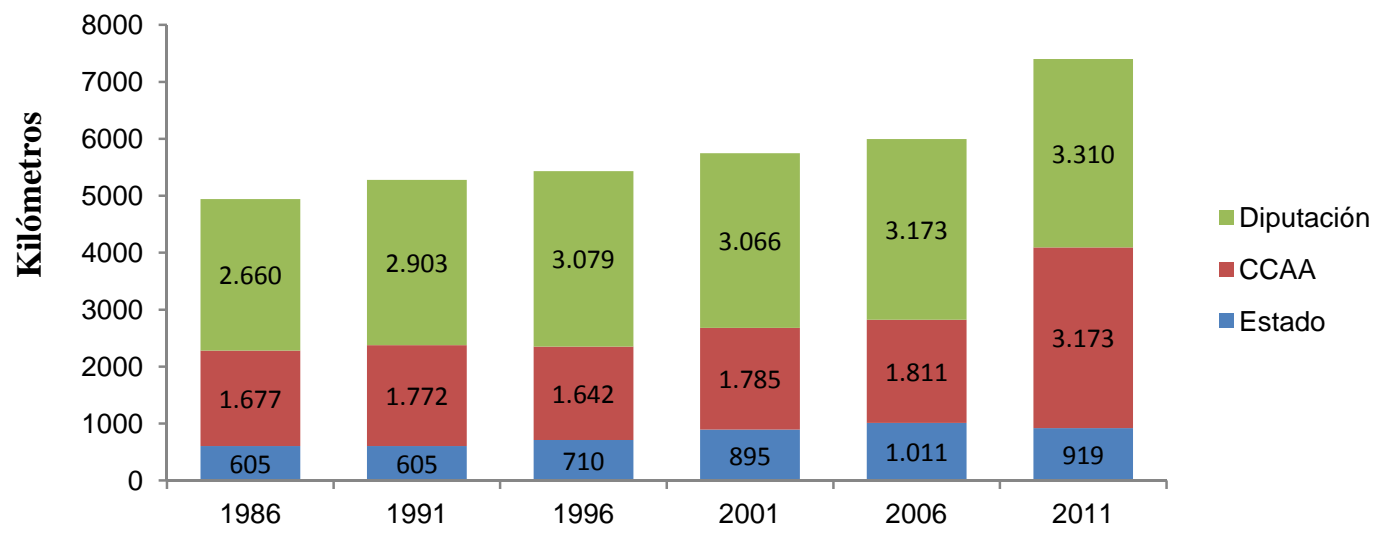

Fuente: Anuario Estadístico de Castilla y León. Varios años.

Esta red y sus características son el resultado de las inversiones reflejadas en los Gráficos 6 y 7 , que diferencian la procedencia de la finan- ciación (del Estado, de la Comunidad Autónoma o de la Diputación Provincial).

\section{Gráfico 6}

Inversiones del Estado en construcción de carreteras. Total y según Administración responsable
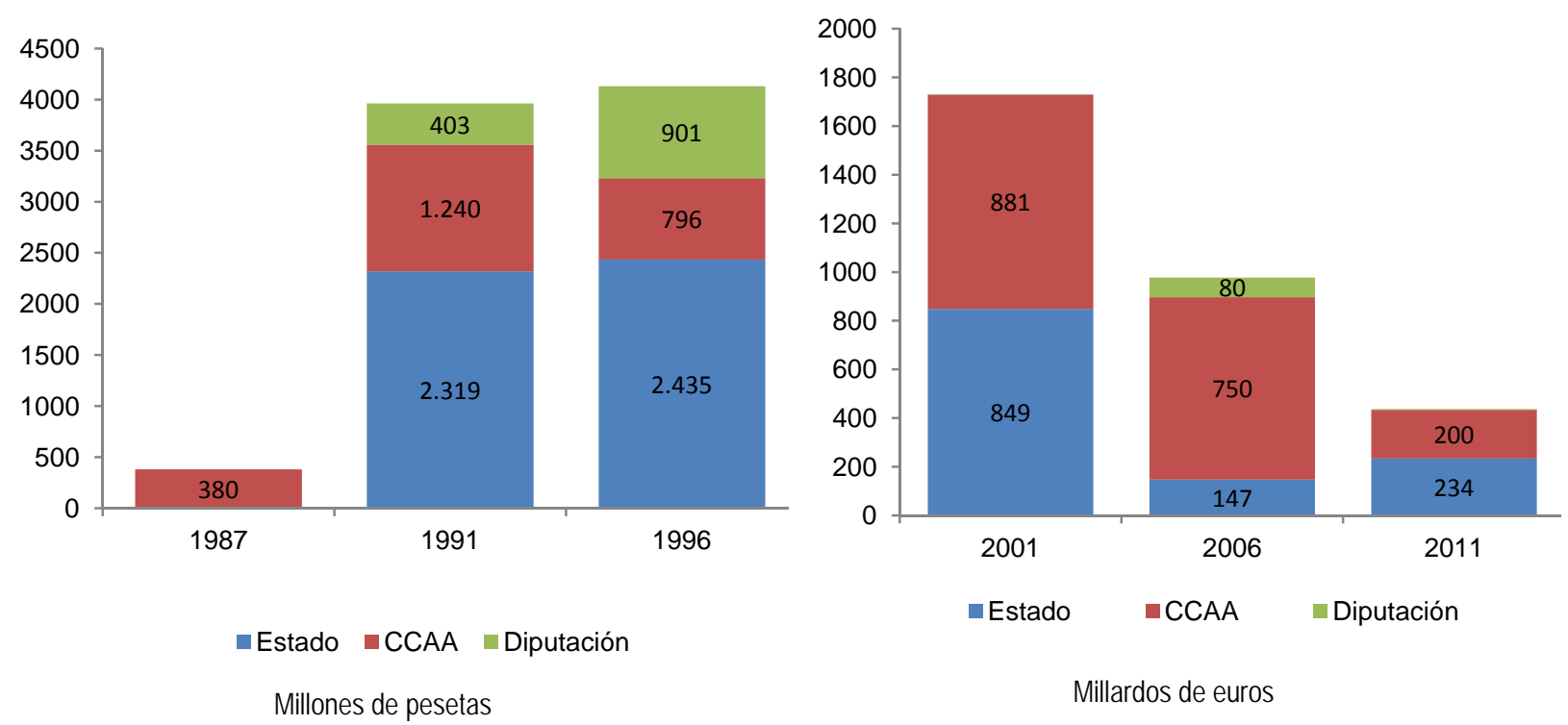

Nota: No se reflejan las inversiones del Estado en el año 1986.

Fuente: Anuario Estadístico de Castilla y León. Varios años. 


\section{Gráfico 7}

Inversiones del Estado en reposición de carreteras. Total y según Administración responsable
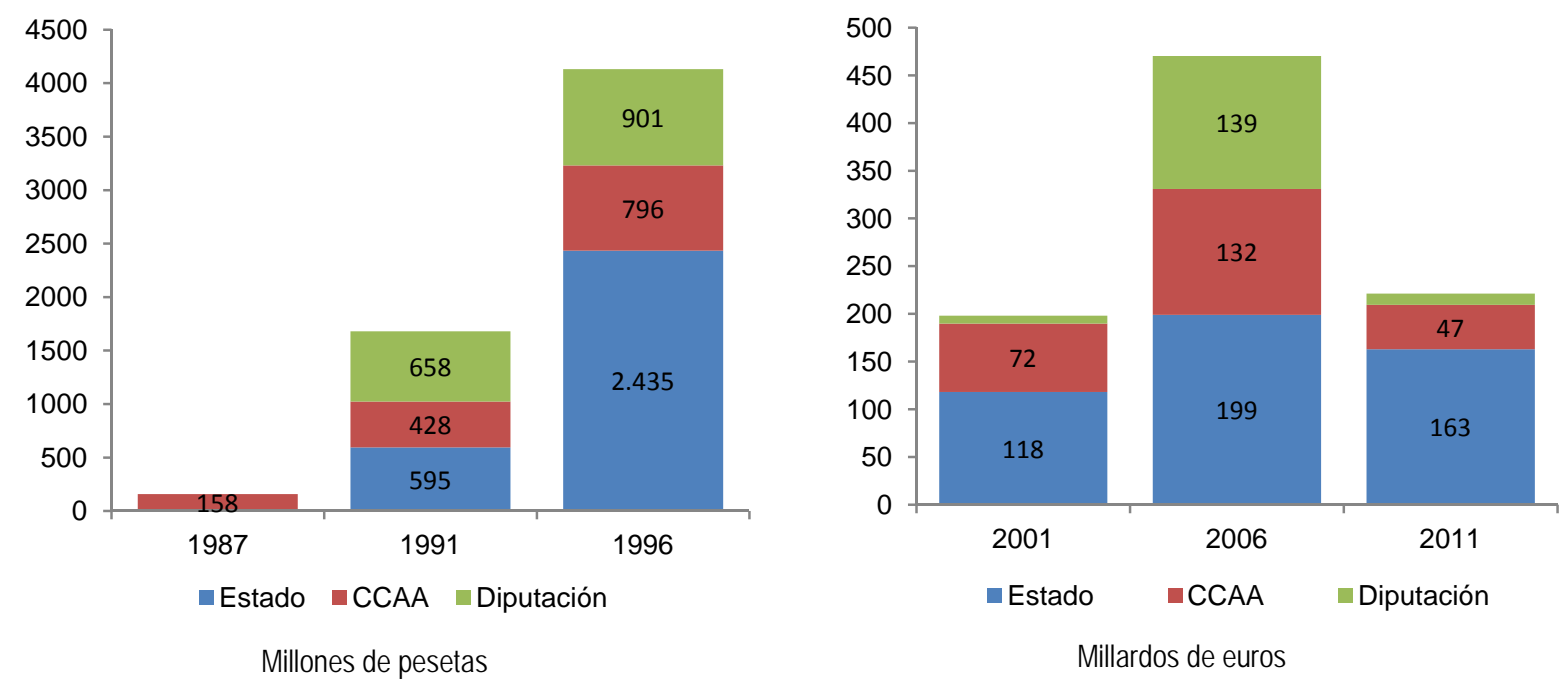

Fuente: Anuario Estadístico de Castilla y León. Varios años.

\subsubsection{Red de cameteras del Estado}

Por la provincia de León transcurren 920 km de vías de titularidad estatal, que son las de mayor capacidad. Entre ellas están las dos autopistas de peaje que corren por la provincia de León (AP-66: Campomanes-León y AP-71: LeónAstorga), construidas mediante concesiones del Estado Español, también responsable de los siguientes tramos que suponen alrededor del $76 \%$ de los kilómetros de autovías libres y del $68 \%$ de los kilómetros de carreteras de doble calzada provinciales:

a) A-6 Madrid-La Coruña, Autovía del Noroeste. Es el eje de mayor longitud, con más de 150 $\mathrm{km}$ de recorrido, todos ellos autovía o autopista libre. Esta vía de gran capacidad tiene un trazado paralelo a la antigua $\mathrm{N}-\mathrm{VI}$, eje de similar extensión que se sigue manteniendo para la comunicación intermodal.

b) N-630 Gijón-Sevilla, Ruta de la Plata. Este eje de aproximadamente $115 \mathrm{~km}$ recorre la provincia de norte a sur garantizando las comunicaciones con Asturias y Madrid. La materialización de la autovía A-66 (55 km de longitud), de trazado paralelo a la $\mathrm{N}-630$, y su continuidad a través de autopista de peaje
AP-66 León-Campomanes permite la realización íntegra de este trayecto a través de vías de gran capacidad.

c) N-120 Logroño-Vigo, tiene un recorrido en sentido este-oeste de aproximadamente 80 $\mathrm{km}$, muchos de los cuales han perdido protagonismo al inaugurarse autovías o autopistas de trayecto similar.

d) La N-621, León-Unquera (Cantabria) y la N625, Mansilla de las Mulas-Arriondas (Asturias) son las vías que canalizan las comunicaciones del cuadrante nororiental de la provincia con destino a Cantabria y Asturias, con tramos de aproximadamente 80 $\mathrm{km}$ cada una de ellas.

e) La N-601 Madrid-León por Valladolid tiene un recorrido en la provincia de aproximadamente $50 \mathrm{~km}$ que se verán reducidos cuando se finalice la autovía (A-60) cuya construcción ya ha sido iniciada. De hecho, es esta una de las principales actuaciones que la Administración central está ejecutando en la actualidad ${ }^{5}$.

5 El tramo Puente Villarente-León ya está en funcionamiento. Las obras en los tramos VillanublaValladolid y Puente Villarente-Santas Martas están en lenta ejecución, pero los trabajos en el tramo intermedio Santas Martas-Villanubla apenas tienen aprobada la declaración de impacto ambiental. 


\subsubsection{Red de cameteras de la Comunidad Autónoma}

La red autonómica, gestionada por la Junta de Castilla y León, se divide en Red Básica y Red Complementaria. La Red Básica, que en León abarca 464 kilómetros y está dividida en unos 65 tramos, comprende aquellas infraestructuras destinadas, principalmente, al tráfico de largo recorrido e incluye las carreteras con mayor intensidad de circulación o que tienen una función esencial en la estructuración y ordenación del territorio. En esta categoría se enmarcan las autovías, de las que dos discurren por la provincia de León (la A-231 o Autovía del Camino de Santiago que une León con Burgos, y la CL-631 en su tramo entre Cubillos del Sil y Toreno) y las carreteras denominadas $C L-X X X$, que recorren más de 275 kilómetros por la provincia, entre las que se encuentran, por ejemplo, la León-La Bañeza (CL-622) o la Puente Villarente-Boñar (CL-624).

La Red Complementaria atiende a los tráficos de corto y medio recorrido y cumple la misión de unir los núcleos de población. Esta red, que abarca 1.303 kilómetros en la provincia de León, se subdivide en:

- Red Complementaria Preferente: formada por las carreteras que conectan todas las cabeceras comarcales y núcleos de población superior a 1.500 habitantes.

- Red Complementaria Local: formada por las carreteras accesorias a las redes anteriores, que sirven al tráfico de corto recorrido y tienen una función que trasciende la puramente local de las redes provinciales de las Diputaciones.

Las carreteras leonesas pertenecientes a la Red Complementaria autonómica, se nombran con las siglas LE seguidas de tres cifras identificativas de su zona. De entre estas, merece la pena resaltar la carretera de mayor recorrido, la CL-626 (Valderrueda-Villablino), con casi $170 \mathrm{~km}$ de longitud, que es el auténtico eje vertebrador de las comunicaciones en la montaña norte y la LE-126 (66,1 km), que ejerce similar papel al unir Castrocontrigo con el límite provincial con Orense por Truchas, en el extremo suroccidental de la provincia. También se encuentran dentro de este grupo, por ejemplo, la LE-232 de Sahagún (N-120) a Puente Almuhey (CL-626) o la LE-512 de Mansilla de las Mulas (N-601) a Valderas (L.P. Zamora) por Valencia de Don Juan.

\section{Plan Regional Sec torial de cameteras 2008- 2020}

El Plan Regional Sectorial de Carreteras 2008$2020^{6}$ pretende crear una "red de carreteras de titularidad de Comunidad Autónoma que complemente el Sistema de comunicación interregional e internacional, así como la conservación del patrimonio viario de la región, que permita mejorar la competitividad económica, y la fijación de población en la región, elementos indispensables para el progreso y desarrollo de Castilla y León". La inversión prevista en la provincia de León por este Plan asciende a 1.163,81 millones de euros, un 21,5\% del total, que se repartirán en dos grandes programas: Modernización y Conservación, como se puede observar en el Cuadro 1.

Se espera que la ejecución de este presupuesto incremente en $184,1 \mathrm{~km}$ la longitud de la red de carreteras de titularidad de la comunidad de Castilla y León, y que en la provincia se concrete en la construcción o incorporación a la red autonómica de las siguientes carreteras:

- Conexión Ponferrada-La Cabrera (55,0 km)

- Conexión La Cabrera-L.P. Zamora (23,0 km)

- Carretera Truchas-Llamas de Cabrera (38,8 $\mathrm{km}$ )

- Conexión LE-510-N- 630 (6,6km)

- LE-482 Pinos-L.C. Asturias (7,7 km)

\footnotetext{
6 Aprobado por Decreto 24/2009, de 26 de marzo (BOCyL, 6 de abril de 2009).
} 
Cuadro 1

Inversiones previstas en la provincia de León por el Plan Regional Sectorial de Carreteras (2008-2020)

\begin{tabular}{|l|c|c|}
\hline \multicolumn{2}{|c|}{ Programa de modernización } \\
\hline Subprograma & Longitud (Km) & Inversión (M€) \\
\hline Acondicionamientos & 257,8 & 132,74 \\
\hline Mejoras & 395,5 & 109,41 \\
\hline Nuevas carreteras & 18,3 & 36,60 \\
\hline Variantes & 55,5 & 131,75 \\
\hline Autovías y accesos a ciudades & 99,2 & 424,25 \\
\hline Total programa modernización & $\mathbf{8 2 6 , 3}$ & $\mathbf{8 3 4 , 7 5}$ \\
\hline
\end{tabular}

\begin{tabular}{|l|c|c|}
\hline \multicolumn{2}{|c|}{ Programa de conservación } \\
\hline Subprograma & Longitud (Km) & Inversión (M€) \\
\hline Refuerzos & $1.223,7$ & 172,06 \\
\hline Conservación contratada & - & 63,00 \\
\hline Seguridad vial & - & 36,00 \\
\hline Conservación directa & - & 20.00 \\
\hline Señalización & - & 11,00 \\
\hline Balizamiento & - & 9,00 \\
\hline Total programa conservación & $\mathbf{1 . 2 2 3 , 7}$ & $\mathbf{3 2 9 , 0 6}$ \\
\hline
\end{tabular}

Fuente: Junta de Castilla y León (2009): Plan Regional Sectorial de Carreteras 2008-2020.

Además, a la finalización del Plan ninguna carretera de la red debería tener un ancho de calzada inferior a $6,00 \mathrm{~m}$ y prácticamente la totalidad de la red debería disponer de arcenes pavimentados. Para mejorar el nivel de servicio, se prevén actuaciones específicas en los siguientes tramos de la red leonesa:

- CL-622: De León a La Bañeza-Autovía

- CL-623: De San Andrés del Rabanedo a Lorenzana (Cruce con LE-129-14) - Desdoblamiento

- CL-626: De La Magdalena a La Robla-Autovía

- CL-626: De Villablino a Piedrafita-Autovía

\subsubsection{Red de cameteras de la Diputación de León}

Respecto a las carreteras gestionadas por la Diputación de León, la red tiene una longitud de $3.310 \mathrm{~km}$, todos ellos de carreteras convencionales de diferente anchura. Tras la elaboración del nuevo Catálogo de Carreteras Provinciales aprobado por la Diputación en 2010, su nomenclatura está en proceso de cambio, desde la utilización de las siglas CV (Camino Vecinal) seguidas de las tres cifras que identifican la hoja del IGN en la que empieza la vía y las dos cifras con el número de orden en la hoja, por una identificación más sencilla que comienza por la siglas LE seguidas de cuatro dígitos.

Como recoge la Encuesta de Infraestructuras y Equipamiento Local-Fase 2010 elaborada por la Diputación de León, a pesar de ser la red con menor intensidad de tráfico en términos absolutos, con 747 tramos catalogados y una longitud media por tramo de $4 \mathrm{~km}$, continúa siendo el eje fundamental que sustenta la comunicación de los numerosos núcleos de población con sus cabeceras municipales y con los centros de servicios, aportando también la necesaria densificación para garantizar los enlaces entre las carreteras autonómicas y estatales. La mitad de la red está constituida por tramos de 5 metros de ancho, siendo minoritarios los superiores a 8 metros $(9,2 \%$ del total) y un elevado porcentaje de tramos presenta dificultades debido a las pendientes excesivas (en casi el $35 \%$ de la red) y los estrechamientos (en el $30 \%$ de la misma). 
Por su parte, el Plan Regional Sectorial de Carreteras 2008-2020 prevé ayudar en la financiación de determinadas obras a realizar en las Redes Provinciales dada la funcionalidad de la Red de las Diputaciones, que completa el esquema viario de las carreteras de la Comunidad.

\subsubsection{Estaciones de autobuses}

Aunque se analizan poco al hablar del sector del transporte, las estaciones de autobuses y más específicamente, las condiciones y la calidad de los servicios que en ellas se prestan, son fundamentales para proporcionar un adecuado servicio a los ciudadanos viajeros.

En la provincia de León, la estación más grande se sitúa en la capital, fue construida en 1990, es de titularidad autonómica y se gestiona mediante concesiones. También hay estación de titularidad autonómica en Ponferrada, Astorga y Villablino, así como de titularidad local en otras poblaciones como Santa María del Páramo o Mansilla de las Mulas.

\subsection{Infraestructuras femoviarias}

Las infraestructuras ferroviarias (estaciones de viajeros, centros logísticos y vías) se encuentran bajo la titularidad del Estado, y hasta breves fechas han sido gestionadas por dos empresas: ADIF y FEVE.

En la provincia de León hay cuatro estaciones (Astorga, León, Ponferrada y Sahagún) y ocho instalaciones logísticas (Astorga, Busdongo, la empresa Cosmos, La Robla, León, Ponferrada, Sahagún y Toral de los Vados). La estación de León sustituye desde 2011 a la histórica Estación del Norte, que fue clausurada al tráfico con motivo de las obras que supondrán la llegada de la alta velocidad a la ciudad leonesa. No obstante, esta nueva estación, que tiene carácter terminal, fue planificada como una infraestructura provisional hasta la construcción de la nueva estación soterrada que en la actualidad está siendo objeto de polémica.

ADIF gestiona las vías, donde se incluyen plataformas, raíles, electrificación, señalización, construcción de viaductos, túneles, etc. de las líneas convencionales provinciales hacia el norte (Asturias), oeste (Galicia) y sureste (Palencia), desde donde se accede a Cantabria, Madrid o el País Vasco.

\section{Mapa 1}

Red ferroviaria convencional de ADIF en León

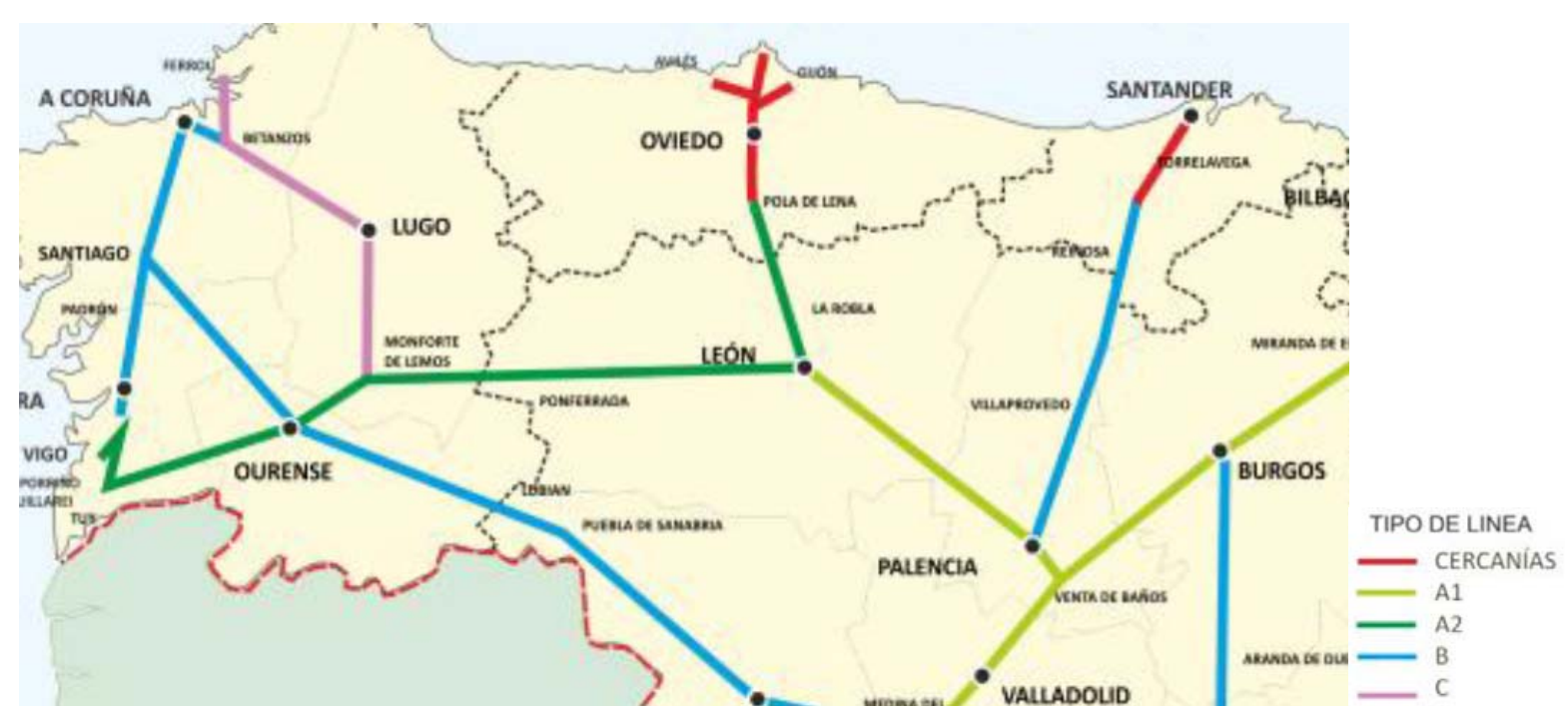

Fuente: Plan de Infraestructuras, Transporte y Vivienda (PITVI) 2012-2024, pág. II.34. 
Mapa 2

Paradas de la red

ferroviaria de ADIF en

León

Fuente: Renfe Operadora.

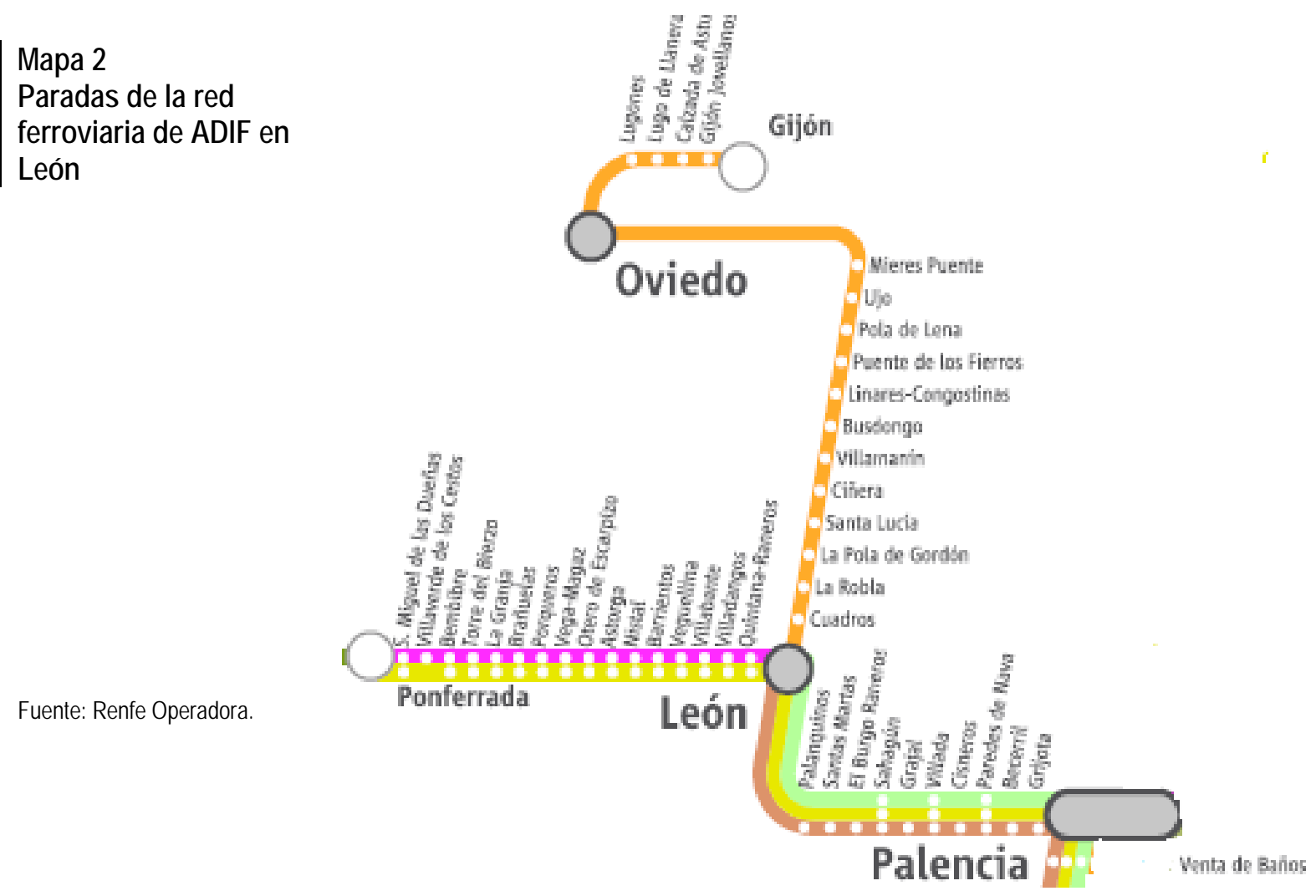

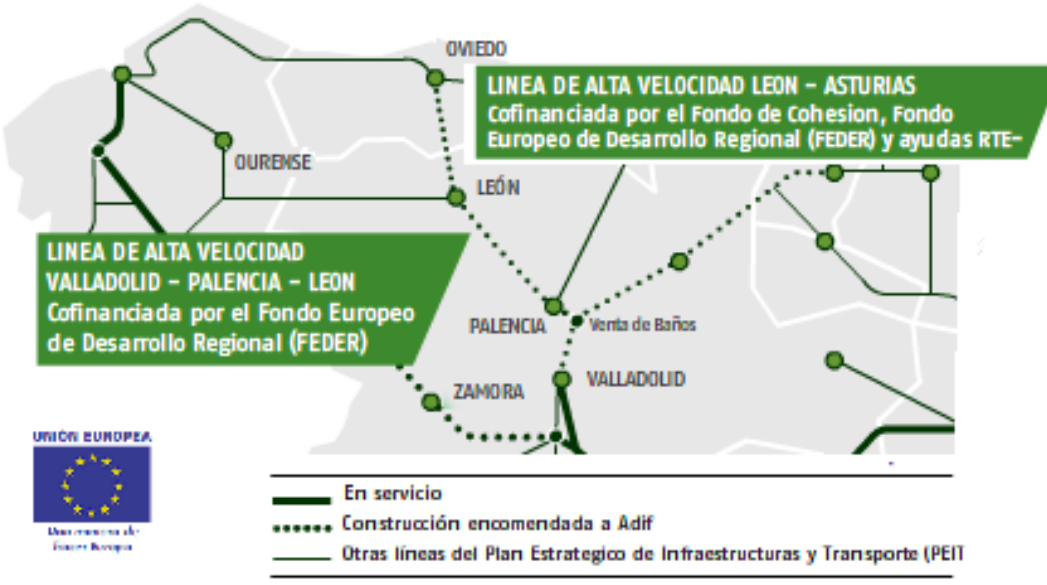

Fuente: ADIF.

\section{Dodif Red alta velocidad
Mapa 3
Red de alta velocidad prevista en León

ADIF también gestiona las infraestructuras de Alta Velocidad $^{7}$, pero a pesar de que en el Plan Estratégico de Infraestructuras y Transporte (PEIT) 2005-2020 más del 40\% de los fondos se destinaban al ferrocarril de alta velocidad con el objetivo de "multiplicar por diez los kilómetros de red e insertar a los núcleos más habitados de la región en una red de gran capacidad, buscando de esa forma una máxima conectividad de la población en su conjunto", a día de hoy, ninguna

\footnotetext{
7 Se consideran líneas ferroviarias de alta velocidad las líneas especialmente construidas o especialmente acondicionadas para velocidades, por lo general, iguales o superiores a 200 kilómetros por hora.
} 
línea de Alta Velocidad está en servicio en la provincia de León, aunque sí están planificadas y en construcción dos: el tramo Venta de Baños-Palencia-León, y la línea León-Asturias que incluye los túneles de Pajares ${ }^{8}$. Sin duda, uno de los grandes hitos en cuanto a infraestructuras ferroviarias en León (e incluso en cuanto a las infraestructuras en general) sería la llegada a León del AVE procedente de Valladolid, que estuvo prevista para 2010, aun- que los retrasos y la reducción de presupuestos por la crisis lo han hecho imposible.

FEVE gestiona una extensa red ferroviaria de carácter convencional y enfocada a la conexión de núcleos de tamaño mediano y pequeño que está presente, fundamentalmente, en el Norte de España. En lo que atañe a la provincia de León, la red de FEVE une la capital de la provincia con Bilbao.

\section{Mapa 4}

Red ferroviaria convencional de FEVE en León

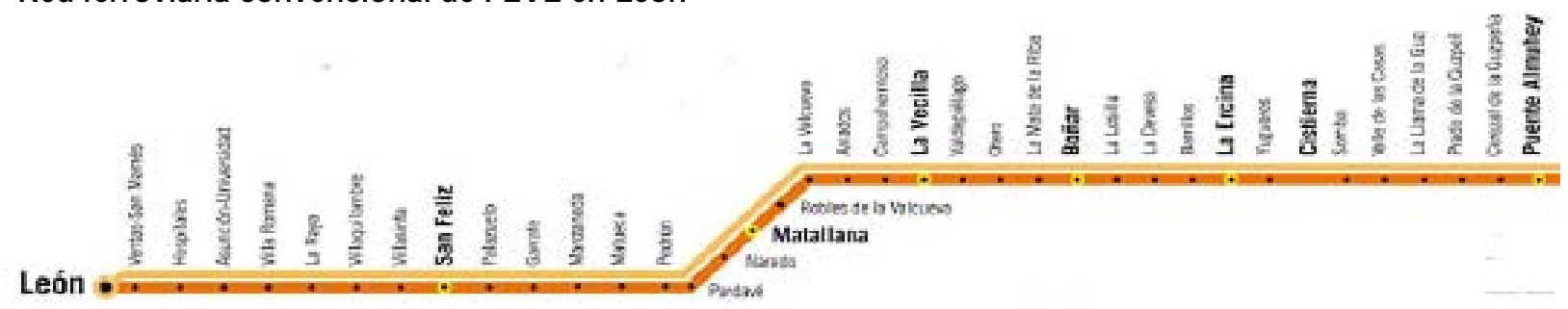

Fuente: FEVE.

\subsection{Infraestructuras aéreas}

Los aeropuertos, junto a los puertos y estaciones de autobús, dado que pueden localizarse en un punto determinado, son consideradas infraestructuras "puntuales", por oposición a carreteras e infraestructuras ferroviarias, clasificadas como "de red". León dispone de un aeropuerto de reducidas dimensiones y escasas prestaciones sito en Valverde la Virgen, heredero de las instalaciones militares existentes desde principios del siglo $\mathrm{XX}$, que fue inaugurado oficialmente en 1999. En la actualidad, es utilizado conjuntamente como base militar y aeropuerto abierto al tráfico civil.

El Aeropuerto de León inició su orientación comercial con una pista de vuelo, una calle de enlace y un estacionamiento, que fueron inau- gurados en julio de 1995 a los que se les añadió un edificio terminal y uno de servicios.

Desde el año 2003, se han realizado sucesivas ampliaciones y mejoras con el objetivo de incrementar el número de pasajeros al que dar servicio. Ese mismo año se construyó un nuevo edificio para el Servicio de Salvamento y Extinción de Incendios (SEI) y en 2005 se amplió la pista hasta los $2.100 \mathrm{~m}$, la plataforma de estacionamiento de aeronaves en $14.600 \mathrm{~m}$, y se llevó a cabo la instalación de un sistema de aterrizaje ILS Cat I para mejorar las operaciones en condiciones de meteorología adversa. En 2007, se concluyó una nueva ampliación de pista hasta los actuales $3.000 \mathrm{~m}$, lo que posibilita operar en él aviones de más de 100 pasajeros con destinos de hasta 4.000 millas náuticas y en 2010 se inauguró un nuevo edificio terminal con un aparcamiento de 295 plazas para turismos y 4 para autobuses

\footnotetext{
8 La Variante de Pajares entre La Robla y Pola de Lena, cuya estructura central es un túnel de base bitubo que atraviesa la cordillera cantábrica tiene una longitud de 49,7 km, está diseñada para doble vía de alta velocidad, en ancho internacional y será apta para tráfico mixto. Cuando entre en funcionamiento, el recorrido entre León y Asturias se reducirá en 33 km y el trayecto entre León y Oviedo se realizará en poco más de 60 minutos. El Programa Operativo del Fondo de Cohesión FEDER 2007-2013 ha contribuido a la financiación de estas obras que se han encontrado con graves problemas técnicos.
} 
Sin embargo, a pesar de todas estas mejoras y de que, desde hace tiempo, se reconoce que los aeropuertos generan efectos económicos y sociales positivos, el aeropuerto de León ha tenido una vida plagada de contratiempos y aún no ha sido capaz de "despegar".

\subsection{Puertos}

En la Unión Europea, el $80 \%$ de las importaciones y exportaciones de mercancías utilizan los puertos marítimos como método de transporte; sin embargo, en la provincia de León no existe ningún puerto seco ${ }^{9}$. En Castilla y León existen dos, uno en Villafría (Burgos) y otro en Venta de Baños (Palencia) y están programados otros tres en las provincias de Salamanca, Valladolid y Burgos, que servirán para completar los servicios de la red CyLoG; por lo que la provincia de León, a pesar de la importantes relaciones que su tejido empresarial mantiene con el Puerto de Gijón, se queda alejada de estas mejoras en las infraestructuras de transporte.

\subsection{E Modelo CyLoG}

En 2005, la Junta de Castilla y León puso en marcha el denominado "Modelo CyLoG de Infraestructuras Complementarias del Transporte de Mercancías y Servicios Logísticos de Castilla y León", con el objetivo de crear una Red integrada de infraestructuras públicas de altas prestaciones para mejorar la eficiencia del transporte en Castilla y León. Como la propia Asociación CyLoG informa, el Modelo pretende ofrecer servicios logísticos de calidad a las empresas de Castilla y León a un precio competitivo, estableciendo puntos de referencia del transporte intra y suprarregionales.

Desde 2007, esta Asociación promociona y gestiona el Modelo bajo la tutela de la Junta de Castilla y León, con la misión de apoyar al sector productivo de Castilla y León a través de

\footnotetext{
9 Un puerto seco es una terminal intermodal interior, conectada por carretera o ferrocarril con una o varias terminales marítimas, con la finalidad fundamental de aumentar sus capacidades de almacenaje (hinterland) al tiempo que se libera espacio en las instalaciones portuarias.
}

la logística, creando un tejido logístico autóctono, analizando las cadenas de suministro de distintos sectores para proponer Sistemas Logísticos Regionales (SLR) y promoviendo la internacionalización de la economía castellano y leonesa (Decreto 16/2007, de 22 de febrero por el que se regula el establecimiento, organización y funcionamiento de las infraestructuras complementarias del transporte de mercancías y de la logística, «Enclaves CyLoG»).

En la provincia de León hay dos Enclaves Logísticos dentro de la Red, uno ubicado en el Polígono de Villadangos y otro en Ponferrada, una Sociedad Gestora (CETILE) y dos Asociaciones de Compras (León y Bierzo). El enclave de León está más avanzado que el de Ponferrada y sus principales datos se recogen en el Cuadro 2.

Junto al diseño y planificación de los enclaves logísticos de ámbito local/provincial el Modelo proyecta un Gran Enclave Logístico Regional del que León también se queda fuera porque su ubicación está prevista en un área de centralidad en el eje de comunicación BurgosPalencia-Valladolid.

\section{Los senvicios de transporte en León}

En las Cuentas Económicas de España y la Contabilidad Regional de España elaboradas por el INE, el sector que nos ocupa forma parte de la Rama Transportes y Comunicaciones o Transporte y Almacenamiento (según la metodología utilizada en el año de análisis), que pertenece a los Servicios destinados a la venta o a los Servicios de mercado (también dependiendo de la metodología), pero no disponemos de estos datos sectoriales provincializados, sino sólo relativos al conjunto de la Comunidad Autónoma, y dado que la labor de provincializar macromagnitudes excede con mucho los objetivos de este trabajo, nos conformaremos con suponer que, en términos relativos, la estructura productiva provincial coincide con la regional, por lo que aplicaremos una simple regla proporcional para aventurar datos relativos a la provincia de León. 


\section{Cuadro 2 \\ Enclave CYLOG en León}

\begin{tabular}{|l|l|}
\hline Sociedad Gestora: CETILE & \\
\hline Ubicación: Polígono de Villadangos (Chozas de Arriba) & - Completar la actual urbanización en otras $13 \mathrm{Ha}$ \\
$-74.475 \mathrm{~m}^{2}$ de suelo disponible urbanizado & - Más de 40 Ha disponibles para la ampliación \\
Prestación de servicios: & - Construcción de un puerto seco \\
- Estacionamiento vigilado: 225 plazas en parking y 200 & Construcciones previstas: \\
en perímetro de naves & - Adecuación oficinas planta primera $\left(375 \mathrm{~m}^{2}\right)$ \\
- 3 Naves de almacenamiento logístico $\left(14.625 \mathrm{~m}^{2}\right)$ & - Unidad de suministro de carburantes \\
- Estación de servicio, vestuarios, aseos, duchas & - Instalación contra incendios P-3 $\left(4.125 \mathrm{~m}^{2}\right)$ \\
& - Control de accesos al recinto \\
\hline
\end{tabular}

Fuente: www.asociacioncylog.com.

En consonancia con lo dicho al principio del capítulo, como se puede observar en el Gráfico 8, en 1986 los Transportes y Comunicaciones generaban el 4,3\% del Valor Añadido Bruto regional a Precios de Mercado (5,36\% a Coste de Factores) y en 2011 generaron el 3,8\% del
VAB total ${ }^{10}$. Sin embargo, a pesar de la similitud de los datos inicial y final, en los años intermedios ha habido variaciones considerables, pues mediados de los noventa la contribución del sector al VAB llegó a elevarse al $7 \%$ del total ${ }^{11}$.

\section{Gráfico 8}

Peso del VAB de la rama transportes y comunicaciones/transporte y almacenamiento en el VAB total de Castilla y León y España (1986-2011)

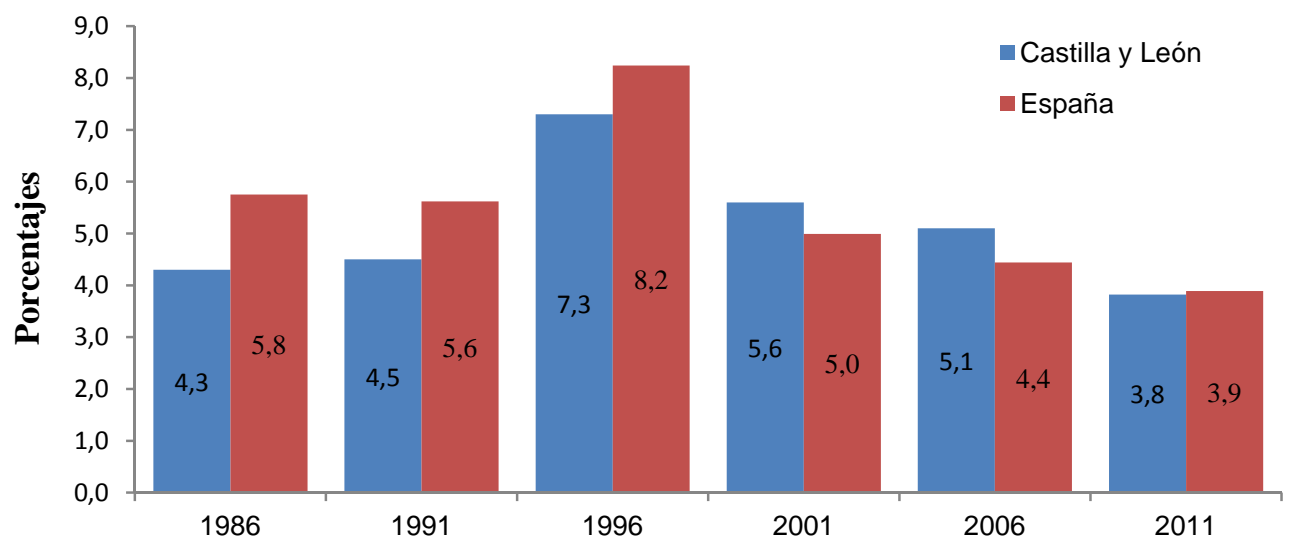

Nota: Rama transporte y comunicaciones hasta 2006, Rama transporte y almacenamiento en el dato de 2011.

Fuente: INE. Contabilidad Regional de España y Contabilidad Nacional de España. Varios años.

10 En España, el Transporte supuso el 5,8\% del VAB total en 1986 y el 4,5\% en 2011 según la nueva metodología de cálculo.

11 Hemos de considerar, no obstante, que los cambios de metodología estadística sufridos a lo largo de un periodo tan extenso de tiempo pueden haber influido en estas variaciones. Por ejemplo, la Contabilidad Regional de España Base 2008, contempla la adaptación a las nuevas clasificaciones de actividades y productos aprobadas en el seno de la Unión Europea y, en consecuencia, los servicios de transporte pasan de estar incluidos en la rama Transporte y Comunicaciones a ser reflejados en Transporte y almacenamiento. 
Si, como decíamos, aceptamos que en la provincia de León el peso relativo de la rama Transporte y Comunicaciones con respecto al sector Servicios es similar al de la Comunidad Autónoma, podemos aventurar que su Valor
Añadido superó los 480 millones de euros en 2008 utilizando la Contabilidad Regional Base 2000 y los 394 millones en 2011 con la nueva metodología de cálculo, tras haber seguido una senda de expansión como muestra el Gráfico 9.

\section{Gráfico 9}

VAB de la rama transportes y comunicaciones/transportes y almacenamiento en León (2000-2011). Base 2000 y 2008 (millones de euros)
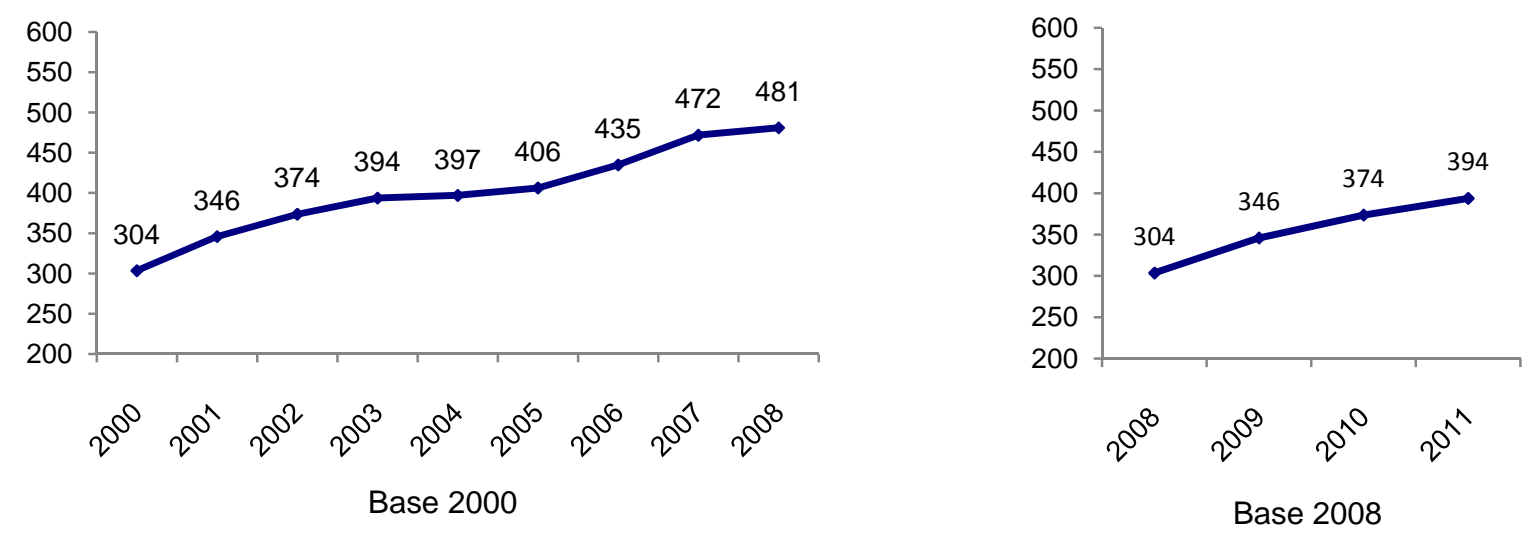

Fuente: Elaboración propia a partir de la Contabilidad Regional de España.

En cuanto al mercado laboral y aplicando el mismo método simple de provincialización, podemos decir que las empresas de la rama Transporte y Comunicaciones empleaban en la provincia en torno a 8.300 personas en 2008 . Al cambiar la metodología de elaboración de las cuentas, los trabajadores de la agrupación Transporte y Almacenamiento ascendían a 7.334 en 2011, con una leve tendencia descendente desde 2009. De estos totales, más del $77 \%$ eran empleados asalariados, nivel similar a la media nacional sectorial. Una de las principales características de las relaciones laborales del sector, junto con la escasa presencia del trabajo femenino y una relativamente reducida tasa de paro, es precisamente este tradicional bajo peso relativo, en relación al resto de sectores, de los asalariados en el empleo total debido al elevado número de autopatronos, por lo que el cambio de estructura laboral hacia una mayor asalarización ha sido objetivo de diferentes planes públicos para el sector, como signo de la modernización del mismo.

\section{Gráfico 10 (a)}

Empleo de la rama transportes y comunicaciones en León (2000-2008)

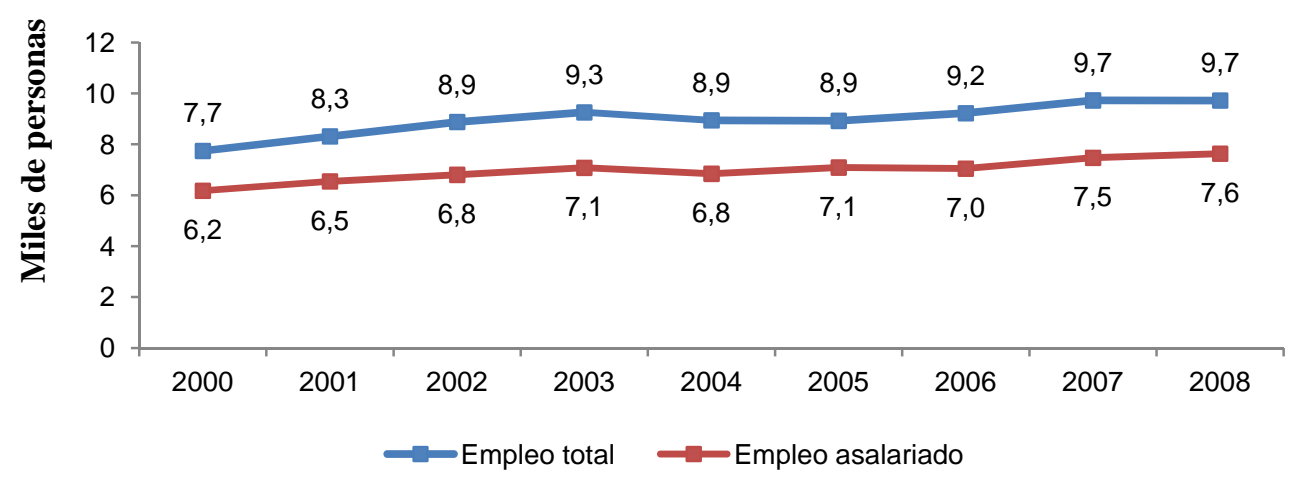


Gráfico 10 (b)

Empleo de la rama transportes y almacenamiento en León (2008-2011)

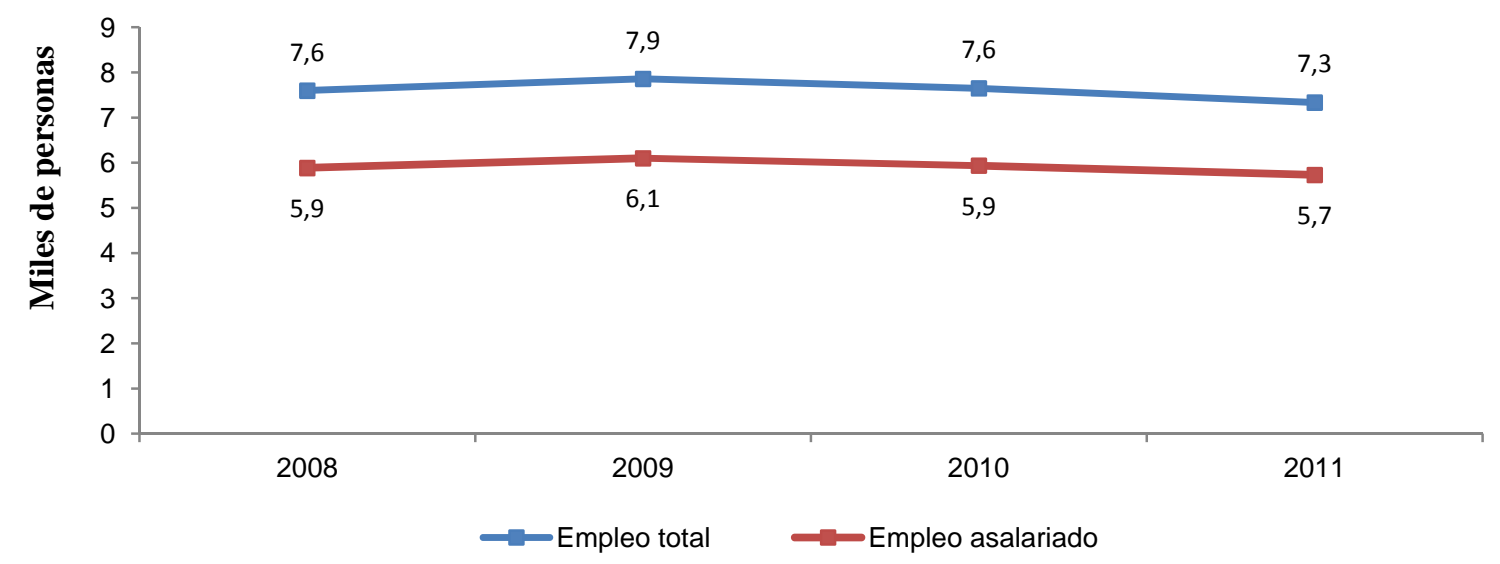

Fuente: Elaboración propia a partir de la Contabilidad Regional de España.

Hemos de tener en cuenta que quizá estas cifras no estén recogiendo en toda su magnitud los efectos que sobre el sector ha tenido la recesión económica por la que actualmente estamos atravesando, que ha implicado una disminución de la actividad productiva y, entre otros factores, se ha caracterizado por una un vertiginoso incremento de los precios del petróleo y por ende, de sus derivados los combustibles fósiles, lo que ha impactado muy negativamente en el transporte de mercancías por carretera.

Según la encuesta que CECALE realizó en 2007 al sector en Castilla y León, el 97,48\% de las empresas transportistas consultadas, siguen desarrollando la misma actividad que desde el origen y el $58,71 \%$ de las mismas no ha variado la carga transportada. Además, a pesar del dinamismo que ha caracterizado tradicionalmente a esta actividad empresarial, tan sólo un 2,52\% de las empresas transportistas han llegado a incorporar en sus operaciones otros servicios complementarios al transporte, fundamentalmente los de organización del transporte (figura de la agencia de transporte y de los transitarios), mientras que en porcentajes aún inferiores lo han hecho ampliando su oferta a servicios de depósito y almacenamiento de mercancías y $/ 0$ depósito y manipulación de mercancías.

Si el análisis lo realizamos diferenciando por tamaño de la empresa, se observa cómo las empresas sin asalariados no han experimentado evolución alguna, más allá de la mera variación de la tipología de la carga transportada, pero a medida que se incrementa el tamaño se observa una evolución hacia la incorporación de servicios complementarios, fundamentalmente los de organización del transporte. No hay ninguna razón para pensar que estas tendencias no se reproduzcan en las empresas leonesas que, por otra parte, han sido parte de la muestra encuestada.

Por último, señalaremos que los Servicios de transporte, tanto en España como en la provincia de León, son un grupo inflacionista, con incrementos de los precios mayores que el índice general en los últimos diez años con la excepción de 2010 y 2011, como muestra el Gráfico 11. 
Gráfico 11

IPC general y de los servicios de transporte (2003-2012)

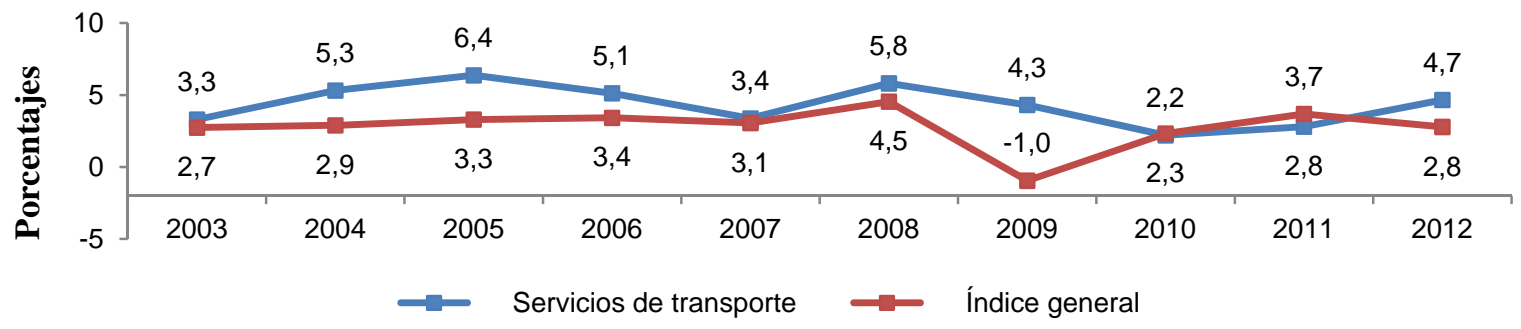

Fuente: INE.

\subsection{Transporte de mercancías}

\subsubsection{Por c arretera}

León no tiene salida natural al mar ni puerto seco, su tránsito ferroviario de mercancías es escaso y prácticamente nulo el tráfico aeroportuario, por lo que la gran mayoría de la actividad de transporte de mercancías se concentra en la carretera. Sin embargo, ningún organismo elabora ni publica datos provinciales sobre mercancías transportadas por carretera, es decir, no podemos analizar en qué nivel se sitúa el volumen de mercancías movidas por este modo ni si los flujos son intra o extraprovinciales, ni podemos, por tanto, estudiar cuáles han sido las variaciones a lo largo de los últimos años. Nos vemos obligados, entonces, a analizar la evolución del sector a través de otras variables indirectas como el número de matricula- ciones de vehículos de carga, las autorizaciones expedidas o el número de empresas dedicadas a la actividad.

Las matriculaciones de vehículos de carga en León han seguido tendencias muy diferentes en función de su Masa Máxima Autorizada (MMA). A pesar de la trayectoria positiva del VAB que hemos visto con anterioridad, desde 1997 la matriculación de camiones grandes (MMA mayor a $3.500 \mathrm{~kg}$ ) disminuyó con respecto al ejercicio anterior en todos los años excepto 1999, 2005 y 2006. Hasta 2007, las rebajas fueron contenidas y en la provincia se matriculaban más de 220 camiones grandes cada año; sin embargo, a partir de entonces el descenso ha sido tan importante, con tasas de variación negativa anual que alcanzaron el 43\%, que en 2011 únicamente se matricularon 55 vehículos de este tipo (39 en 2012).

\section{Gráfico 12}

Matriculaciones de camiones y furgonetas. Provincia de León (1986-2011)

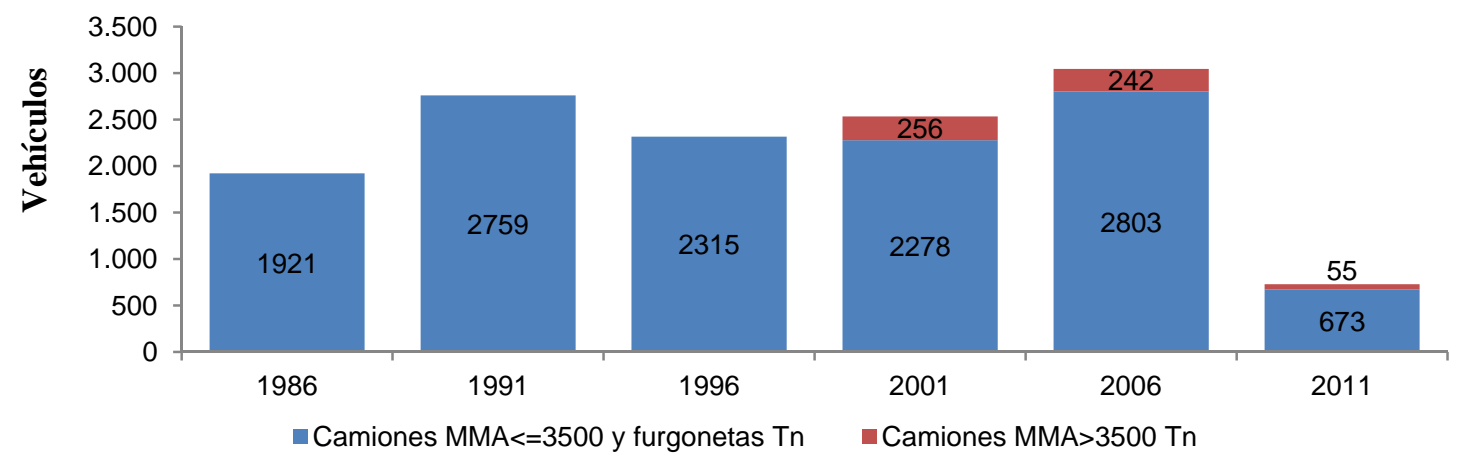

Nota: Hasta 1996 los datos están sin desagregar y sólo se dispone de número de matriculaciones de "Camiones", sin diferenciar en función de su MMA. Fuente: DGT. 
La evolución de las matriculaciones de camiones con MMA menor o igual a $3.500 \mathrm{Kg}$ y de las furgonetas, ha acusado en mayor medida las pequeñas variaciones en el entorno económico y en la particular legislación, fundamentalmente fiscal, que afecta al sector. Por lo tanto, apreciamos hasta cinco etapas claramente diferenciadas: después de importantes disminuciones a principios de los años noventa, hasta 1999 las matriculaciones se incrementan ligeramente, disminuyen en los tres años siguientes hasta niveles inferiores a los del inicio del periodo y en 2003 empieza una acusada recuperación que alcanza sus puntos máximos en 2007 en torno a los 2.800 vehículos matriculados. A partir de aquí, se reproduce el trágico escenario de los camiones grandes: en 2008 solo se matriculan 1.488 camiones pequeños y furgonetas y la reducción continua hasta los 673 vehículos de 2011 (494 en 2012), un $76 \%$ menos que en $2007^{12}$. Como resultado global e histórico, en 2012 (último dato disponible) el parque móvil leonés de vehículos para el transporte de mercancía ascendía a 59.140 unidades, que suponen el $1,19 \%$ del total nacional y el $21,3 \%$ del total autonómico, lo que convierte a León en la provincia con mayor parque móvil de estas características en la Comunidad Autónoma.

\section{Gráfico 13}

Distribución provincial del parque móvil de camiones y furgonetas. Castilla y León (2012)

Fuente: DGT.

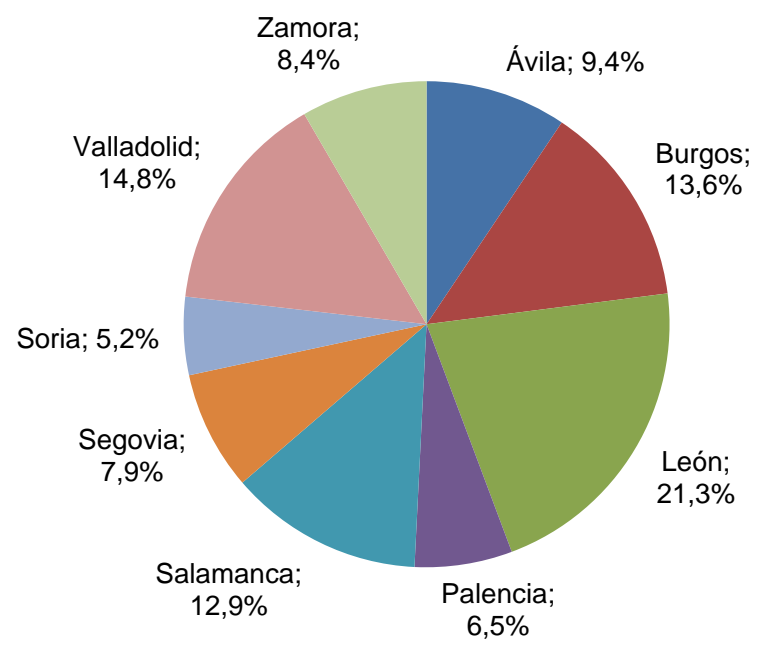

\section{Autorizaciones}

A finales de 2012, según los Datos del Registro del Ministerio de Fomento, había en León 2.842 autorizaciones nacionales de servicio público en vehículos pesados, 571 para vehículos ligeros y otras 265 para vehículos pesados MDP, lo que hace un total de 3.678 autorizaciones, el $17,4 \%$ de las otorgadas en la Comunidad de Castilla y León (cuatro puntos menos que el peso relativo provincial en el parque móvil de vehículos de carga). De Servicio Privado, en la misma fecha había 2.104 autorizaciones para vehículos pesados.

Según los datos del Anuario Estadístico de la Junta de Castilla y León 1988, en el año 1986 había en León 15.148 vehículos autorizados para prestar servicios de transporte de mercancías, de los cuales 7.030 realizaban "Servicios Propios" y 3.067 "Servicios Privados". En conjunto, su peso relativo en el total de vehículos similares de la Comunidad Autónoma se elevaba al 23,8\%.

12 El calificativo trágico es, ciertamente, adecuado si tenemos en cuenta el elevado número de autónomos, propietarios de vehículo que hay en el sector. 
Según la misma fuente, había en León 1.432 empresas de Servicio Público, (1.122 correspondientes a transporte pesado y 310 a transporte ligero) y otras 1.136 de Servicio Privado. En relación al censo de la Comunidad Autónoma, estas cifras suponen el 19,3\% y el 17,2\% del total.

En León, el número medio de autorizaciones por empresa asciende a 1,43 dato que, desagregado, corresponde a 2,77 autorizaciones por empresa de servicio público pesado y a 1,84 autorizaciones por empresa de servicio público ligero. Frente a esta cifra, la media nacional sitúa el número medio de autorizaciones de servicio público pesado/ empresa en 3,33, y en 1,93 autorizaciones de servicio público ligero/empresa, para un total medio de autorizaciones de servicio público/ empresa de 2,74.

\section{Empresas IAE}

Según las bases de datos del Impuesto de Actividades Económicas, durante la década que va entre 1996 y 2006, el número de empresas que en la provincia de León $^{13}$ se dedicaban al transporte de mercancías por carretera se ha movido en torno a las 1.900 (véase Gráfico 14). Sin embargo, en 2010 se aprecia un considerable decrecimiento y solamente estaban registradas como tal 1.679 empresas.

\section{Gráfico 14}

Empresas registradas en el epígrafe "transporte de mercancías por carretera" del IAE (provincia de León, 1996-2010)

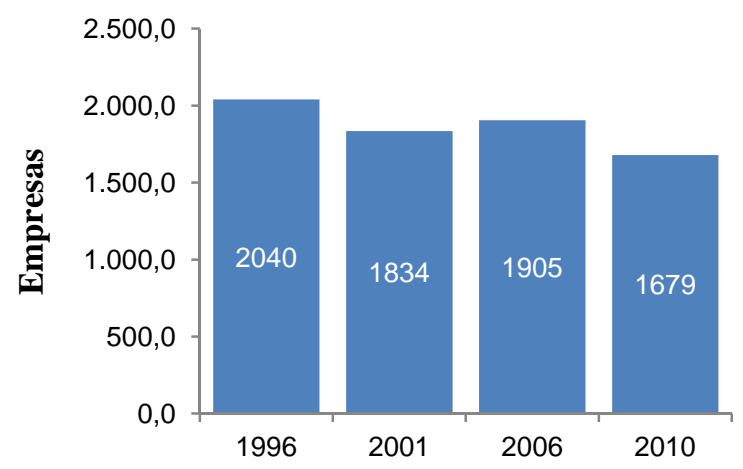

Fuente: Datos proporcionados por la Cámara de Comercio de León.

13 Excluidos los municipios del partido judicial de Astorga.

\subsubsection{Fenoviario y aéreo}

En León, al igual que en el conjunto de España, el ferrocarril es marginal en el transporte de mercancía, por la ausencia de voluntad política, que ya en anteriores planes de infraestructuras decidió apostar por el transporte de viajeros de Alta Velocidad lo cual ha dejado sumido en una evidente ineficacia el transporte de mercancías por ferrocarril.

La segregación de RENFE, en vigor desde el 1 de enero de 2005, fue el inicio de un proceso que está dando fin a un monopolio de más de sesenta años en la prestación de servicios ferroviarios en España. A partir de ese momento, la compañía estatal no fue la única con capacidad para operar en la red, como hemos dicho, gestionada por Adif, y se inició una paulatina introducción de nuevos operadores que comenzó por el transporte de mercancías y finalizará con la liberalización total del transporte de pasajeros. A partir del 1 de enero de 2006, se han otorgado licencias europeas a empresas privadas que tienen libre acceso a toda la Red ferroviaria de Interés General del Estado español para realizar transporte de mercancías internacional o nacional. RENFE tiene habilitación para el transporte de mercancías (y viajeros) en la red ferroviaria estatal.

En cualquier caso, y a pesar de que la evolución no muestra una tendencia uniforme, el resultado para la provincia de León es que cada vez se utiliza menos el ferrocarril para cubrir las necesidades de recepción y envío de mercancías. Como podemos observar en el Gráfico 15, las toneladas expedidas por y recibidas en la provincia han descendido desde 1.717 .640 en 1986 al mínimo histórico de 641.677 en 2011, lo que supone una reducción global del $62,6 \%$, si bien es cierto que el dato referido a 2012 aumenta hasta las 735.865 Tn. Durante los años noventa se produjeron pérdidas muy importantes, las tasas de variación anual negativas fueron habituales y en algunos ejercicios llegaron al 33\% (1992). Durante algunos años de la década de 2000, coincidiendo con una mayor preocupación social por las cuestiones medioambientales y con el relanzamiento de la actividad ferroviaria en el tráfico de viajeros, esta tendencia decreciente pareció revertirse y en 2007 se alcanzaron 1.426.000 de toneladas transportadas, pero desde entonces, la tendencia volvió a ser negativa. 


\section{Gráfico 15}

Transporte de mercancías por ferrocarril. León (1986-2012)

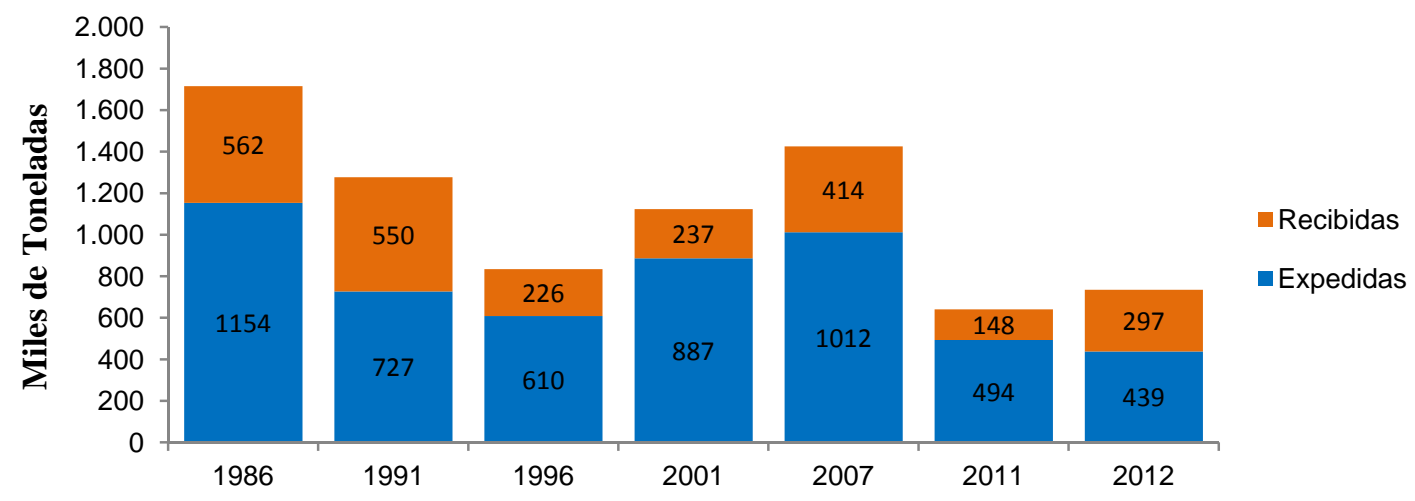

Fuente: RENFE Operadora, recogido en Anuario Estadístico de Castilla y León. Varios años.

Como podemos ver en el Gráfico 16, en 2012 se produce el patrón de los años anteriores y los principales lugares a los que se destinó la mercancía cargada en la provincia fueron las provincias gallegas de Pontevedra, A Coruña y Ourense, que en conjunto recibieron el $77 \%$ de las mercancías expedidas en León.

\section{Gráfico 16}

Distribución provincial de los destinos de las mercancías expedidas por ferrocarril desde la provincia de León (2012)

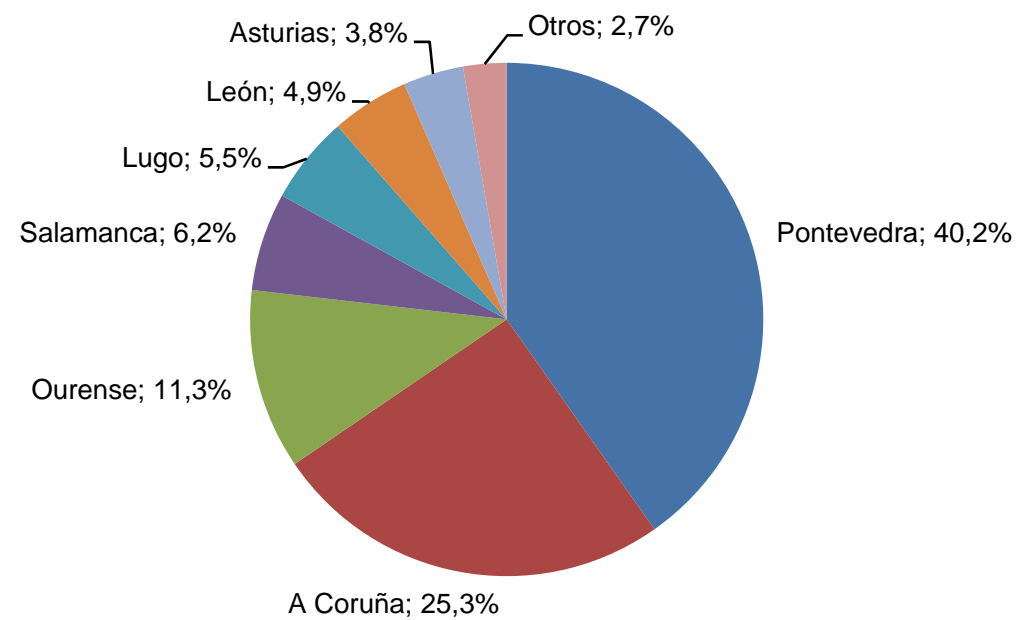

Fuente: Anuario Estadístico de Castilla y León, 2012.

Los principales lugares de origen de las mercancías recibidas fueron Asturias, Cantabria, otras estaciones de la propia provincia, Valen- cia, y Huelva (Gráfico 17), lo que ya da un indicio de la importancia de la agricultura en la utilización del transporte ferroviario. 


\section{Gráfico 17}

Distribución provincial del origen de las mercancías recibidas por ferrocarril en la provincia de León (2012)

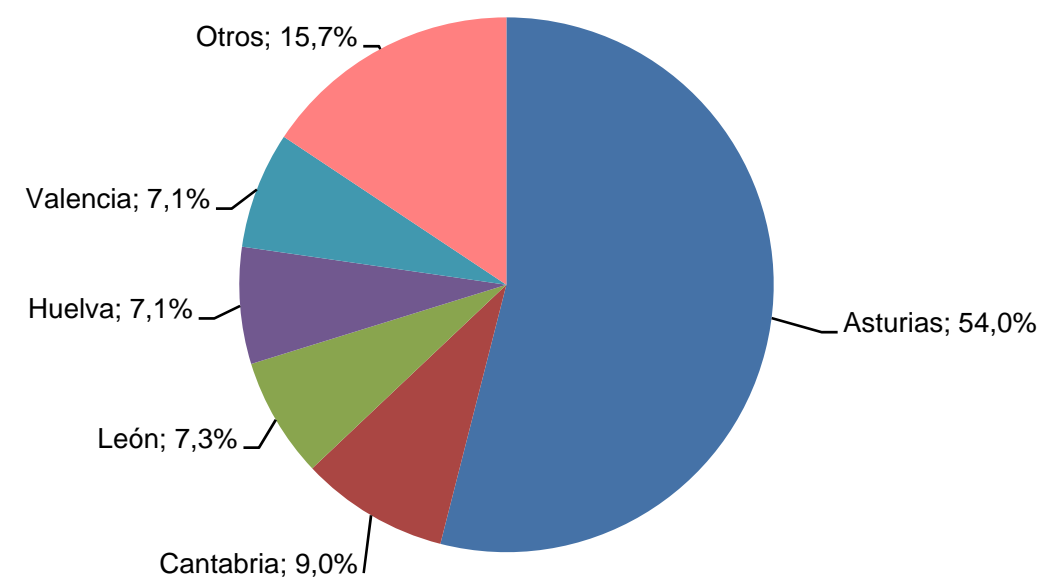

Fuente: Anuario Estadístico de Castilla y León, 2012.

Por su parte, la utilización del transporte aéreo para el transporte de mercancías desde o hacia León es meramente testimonial (Gráfico 18) y aunque en algunos años de la pasada década experimentó cierto crecimiento, fue algo puntuales y en ningún momento ha sido ni siquiera suficientemente importante como para medir ese volumen en toneladas.

\section{Gráfico 18}

Transporte aéreo de mercancías. León (2000-2012)

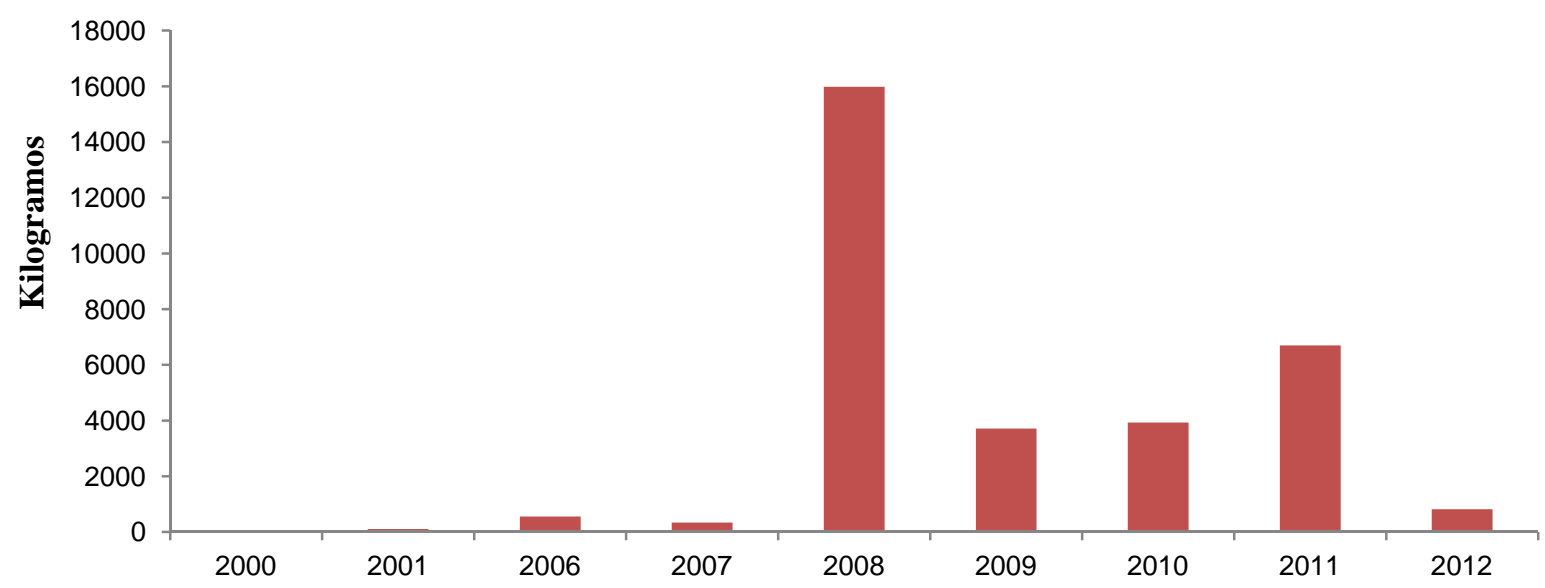

Fuente: INE, SIE y AENA. 


\subsection{Transporte intenurbano de viajeros}

\subsubsection{Por cametera}

Hace años, los Anuarios Estadísticos de Castilla y León recogían datos sobre el número de viajeros que iniciaba o finalizaba viaje en Castilla y León. Sin embargo, este dato dejó de publicarse a finales de los años ochenta por lo que, al igual que en el caso de las mercancías, tendremos que analizar los cambios en la prestación del servicio a través de indicadores como las matriculaciones de autobuses, las autorizaciones o el número de empresas que se dedican a tal actividad.

\section{Matric ulaciones}

La matriculación de autobuses ha seguido una senda creciente aunque con variaciones anuales significativas hasta 2005. Durante ese extenso periodo, se matricularon en León entre 20 y 45 autobuses al año. En el trienio posterior (20062008) este número prácticamente se duplicó y la matriculación anual subió al entorno de 85 vehículos para caer estrepitosamente en 2009 hasta niveles más bajos de los de partida (28 autobuses matriculados), que apenas se han recuperado en los dos años siguientes (véase Gráfico 19), pues en 2011 se matricularon 34 autobuses y en 2012 tan solo 18.

\section{Gráfico 19}

Matriculaciones de autobuses. Provincia de León (1986-2012)

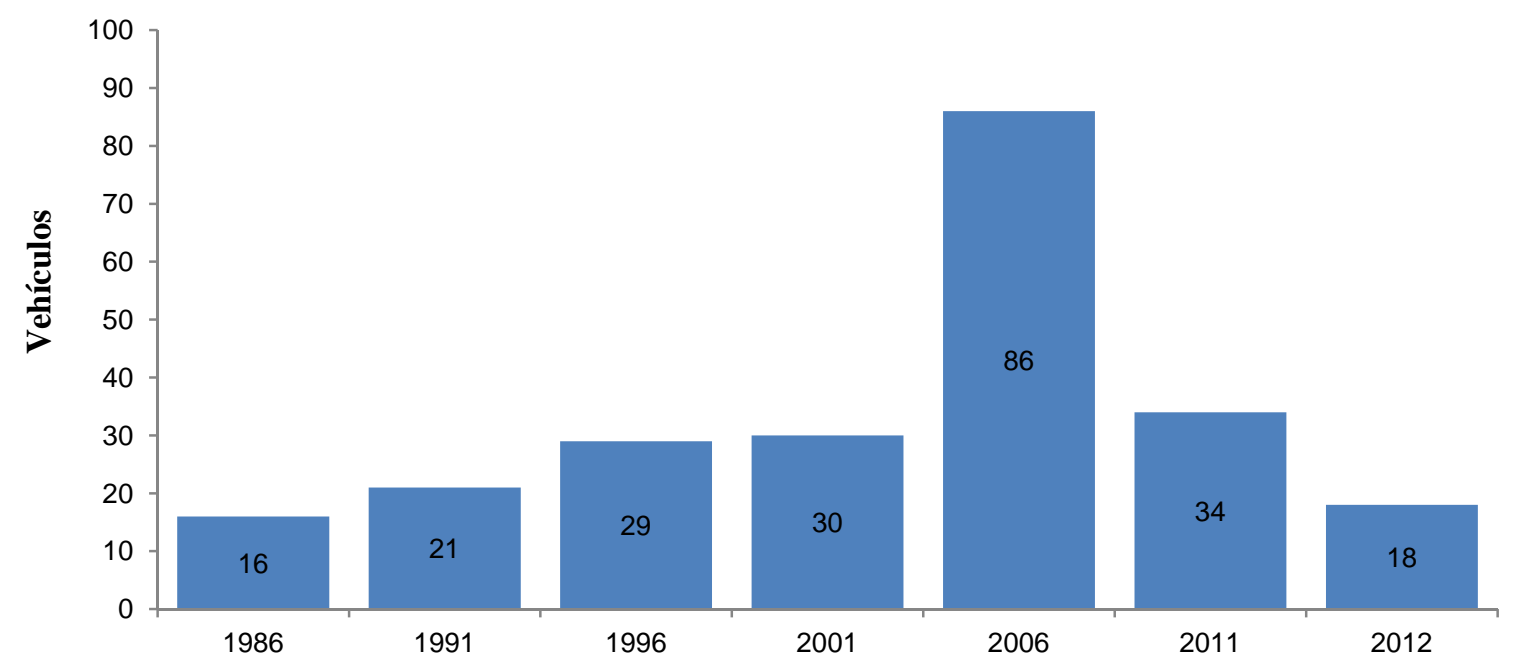

Fuente: DGT.

No obstante, en 2012, el parque leonés de autobuses seguía siendo el mayor de la Comunidad Autónoma y estaba compuesto por
698 vehículos, que representan el 1,14\% del total nacional y el $20,86 \%$ del total autonómico (Gráfico 20). 


\section{Gráfico 20}

Distribución provincial del parque móvil de autobuses. Castilla y León (2012)

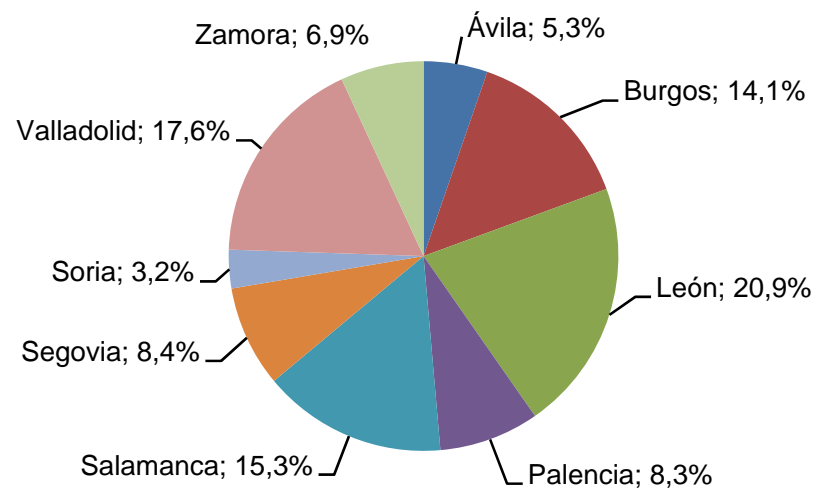

Fuente: DGT.

\section{Autorizaciones}

Según los datos del Anuario Estadístico de la Junta de Castilla y León 1988, en el año 1986 había en León 1.332 vehículos autorizados a prestar servicios de transporte de viajeros, de los cuales 72 se dedicaban al servicio privado. Estas autorizaciones suponían el $25,3 \%$ del total existente en la Comunidad Autónoma.

A finales de 2012, según los Datos del Registro del Ministerio de Fomento, había en León 604 autorizaciones de autobuses de servicio público, y 33 de servicio privado, lo que suponen el $23,37 \%$ y el $40,24 \%$ de las otorgadas en la Comunidad de

\section{Empresas IAE}

\section{Gráfico 21}

Empresas registradas en el epígrafe "transporte de viajeros por carretera" del IAE. Provincia de León (1996-2010)

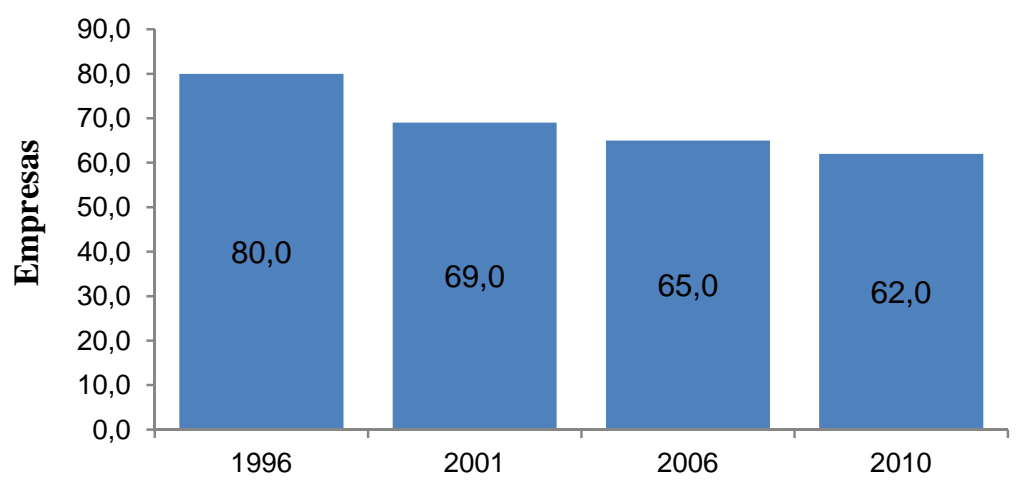

Fuente: Datos proporcionados por la Cámara de Comercio de León. 
Según las bases de datos del Impuesto de Actividades Económicas, durante la década que va entre 1996 y 2006, el número de empresas que en la provincia de León ${ }^{14}$ se dedican al transporte de viajeros por carretera se ha reduciendo paulatinamente hasta las 62 registradas en 2010 (véase Gráfico 21).

\subsubsection{Femoviario y aéreo}

En consonancia con lo dicho en capítulos anteriores, RENFE presta servicios ferroviarios de viajeros y continúa recibiendo del Estado compensaciones por la obligación de prestar el servicio público de transporte a los ciudadanos ${ }^{15}$, fundamentalmente en las líneas regionales y de cercanías, porque las unidades de viajeros de larga distancia y de alta velocidad se gestionan en régimen comercial sometido a competencia de otros operadores.

En el Gráfico 22 observamos claramente la disminución del uso del ferrocarril como medio de transporte de viajeros en la provincia de León ${ }^{16}$. En 1991, primer año reflejado, 1.736.230 viajeros con destino u origen en León utilizaron el ferrocarril; sin embargo, en 2012 apenas lo hicieron 985.505 pasajeros, lo que supone una disminución del 43,2\%.

Pero también es cierto que la tendencia a la reducción del uso del ferrocarril se vio radicalmente detenida gracias a la puesta en funcionamiento, en 2008, del servicio Alvia con

14 Excluidos los municipios del partido judicial de Astorga.

15 El Reglamento (CE) 1370/2007 del Parlamento Europeo y del Consejo, de 23 de octubre de 2007 regula el régimen de los servicios públicos de transporte de viajeros por ferrocarril y carretera y tiene por objetivo establecer las reglas, en virtud de las cuales las Administraciones Públicas pueden intervenir en el sector del transporte público de viajeros para garantizar los servicios de interés general en unas condiciones de frecuencia, calidad y precio que el simple juego de mercado no hubiera permitido prestar.

16 Cuando nos referimos a viajeros, realmente nos estamos refiriendo a "billetes" o a "viajes", pues es evidente que un mismo ciudadano puede realizar varios viajes, por lo que sería contabilizado como varios viajeros. destino Palencia-Valladolid-Madrid. De hecho, como podemos comprobar en el Gráfico 22, la disminución de viajeros se estabiliza a partir de 2007 y en el Gráfico 23 vemos que en el año 2008, el número de viajeros en AVE-Larga Distancia se incrementó más de un $30 \%$ y en 2009 otro $26 \%$ adicional, lo que situó el número de viajeros del servicio en torno a los 500.000 al año, es decir, un $50 \%$ de los ciudadanos que en León utilizan el tren para sus desplazamientos eligen la línea de Velocidad Alta.

En el caso de los viajeros, hay mucha homogeneidad entre los lugares de origen y de destino de los mismos. El $37,8 \%$ de ellos realizan viajes interprovinciales y del $62,2 \%$ restante, la mayoría, el $22,66 \%$ realiza viajes con origen o destino en Madrid.

En 2011, la mitad de los viajeros que se subieron al tren en las estaciones de León se dirigía a Madrid (véase Gráfico 24), que no sólo es destino final, sino que también ejerce de nudo distribuidor de la mayoría de los flujos que se dirigen al sur. El Alvia permite que leoneses abandonen la ciudad a las 6:30 de la mañana, lleguen a Madrid a una hora prudencial para desempeñar tareas profesionales o personales (como las sanitarias) y puedan estar de vuelta en León, como muy tarde a las once de la noche. No nos excedemos si afirmamos que este servicio ha cambiado la distancia entre León y Madrid y la relación de muchos leoneses con la capital. No obstante, la reciente reducción de los servicios ofertados, puede hacer que esta situación no se mantenga. Barcelona, País Vasco y Asturias ocupan los siguientes lugares como destinos favoritos. 


\section{Gráfico 22}

Transporte de viajeros por ferrocarril. León (1986-2012)

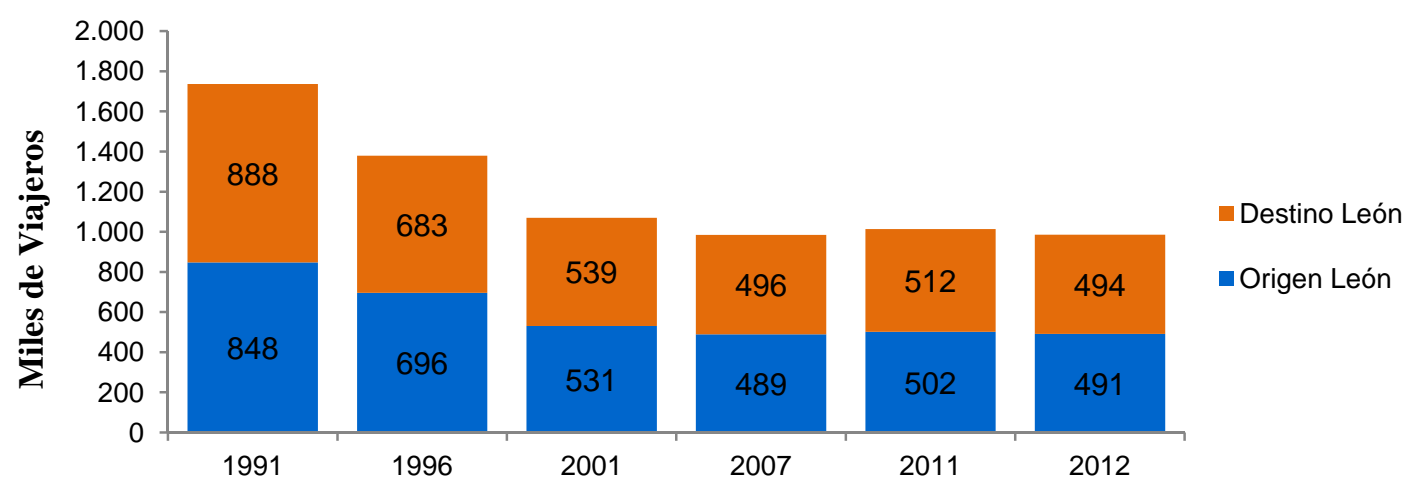

Fuente: RENFE Operadora, recogido en Anuario Estadístico de Castilla y León (varios años).

\section{Gráfico 23}

Transporte de viajeros por ferrocarril en AVE-larga distancia. León (2007-2012)

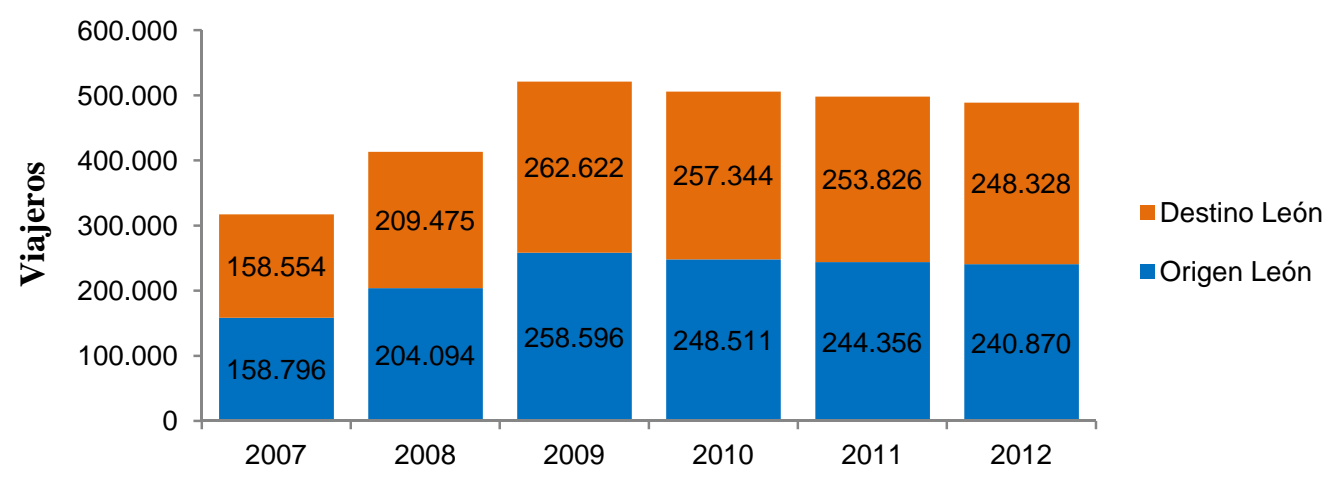

Fuente: RENFE Operadora, recogido en Anuario Estadístico de Castilla y León (varios años).

\section{Gráfico 24}

Distribución provincial del origen de los viajeros por ferrocarril con destino en la provincia de León (2012)

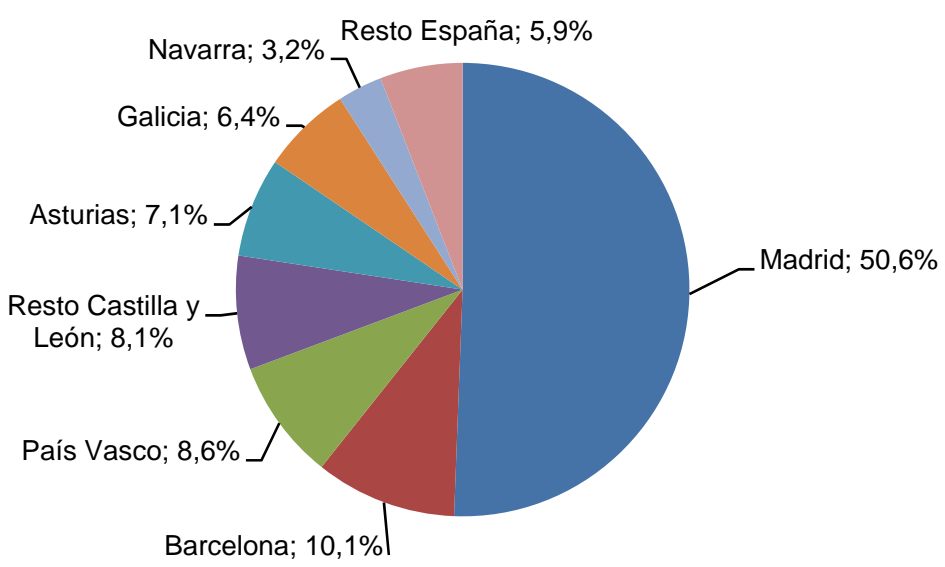

Fuente: Anuario Estadístico de Castilla y León. 2013. 
De la misma forma y por las mismas razones, también es Madrid el origen de la mitad de los viajeros que tienen como destino León. E, igualmente, le siguen Barcelona, resto de
Castilla y León (principalmente Palencia y Valladolid), el País Vasco y Asturias como origen de los viajeros (véase Gráfico 25).

\section{Gráfico 25}

\section{Distribución provincial del destino de los viajeros por ferrocarril con origen en la provincia de León (2012)}

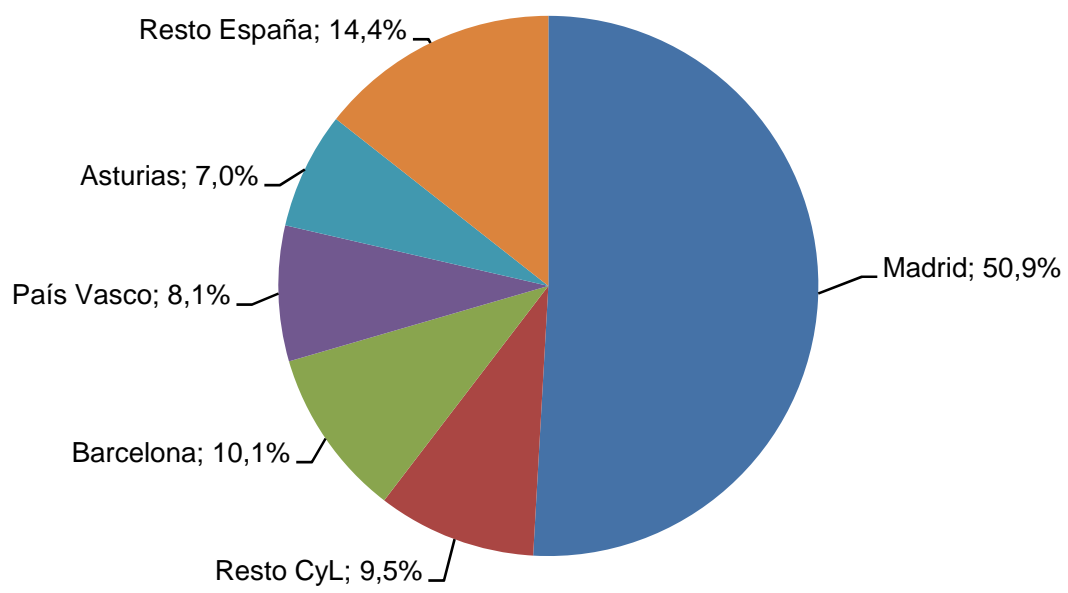

Fuente: Anuario Estadístico de Castilla y León. 2013.

\section{Conclusiones}

Como en cualquier otro lugar y aún más en la provincia de León debido a lo extenso del territorio y a lo dispersa que se encuentra una parte importante de la población, los servicios de transporte son cruciales para el nivel de bienestar de sus habitantes, porque de ellos depende la facilidad de acceso a los lugares de trabajo y ocio o a los servicios públicos básicos como pueden ser los sanitarios o los educativos.

Asumiendo que la estructura de los servicios en Castilla y León se reproduzca en la provincia, la aportación del transporte al VAB leonés se sitúa en torno al $4 \%$ del total y el sector ha pasado de generar en torno a los 300 millones de euros anuales a principios de la década de 2000 , a superar los 480 millones en 2008 y a reducirse a 394 millones en 2011. Sus empresas presentan características también similares al resto de entidades de la Comunidad Autónoma en cuanto a niveles de innovación, de extensión horizontal del proceso productivo (escasa) o de relaciones laborales (elevado nivel de autopa- tronos, escasa presencia del trabajo femenino y relativamente baja tasa de paro), lo que deja clara una vía de mejora en el tejido productivo provincial que habría de explotarse.

Las inversiones realizadas en los últimos veinticinco años han estado centradas, principalmente, en la ampliación y mejora de la red de carreteras y desde el Plan Estratégico de Infraestructuras y Transporte 2005-2020, en el ferrocarril de Alta Velocidad. Como consecuencia, la red de carreteras que transcurre por la provincia de León ha crecido más de un $20 \%$, al pasar de los $4.992 \mathrm{~km}$ en 1986 a los 6.012 en 2011. Más de la mitad de esta red son vías de una sola calzada competencia de la Diputación provincial, mientras que el Estado se hace cargo de casi $1.000 \mathrm{~km}$ correspondientes a vías de gran capacidad (autopistas de peaje, autovías y carreteras de doble calzada) y la Comunidad Autónoma gestiona 3.173 kilómetros de carreteras divididos en Red básica y Red complementaria. La ampliación de la red, con notables excepciones como la A-231 LeónBurgos, ha perpetuado la tradicional estructura 
radial y la pronunciada jerarquización, porque los esfuerzos dedicados a mejorar las vías rápidas han sido mucho mayores que los dedicados a las rutas transversales. Si bien esta jerarquización aporta beneficios importantes al mejorar la relación de León con la capital de España, Asturias y Galicia, igualmente penaliza las conexiones entre poblaciones de mediano y pequeño tamaño y la apertura o mejora de vías de comunicación, mercados y relaciones a todos los niveles con lugares como Bragança o Zamora. También es cierto que, a pesar de la aversión de parte de la población a la dependencia de Valladolid, el retraso en la finalización de la construcción de la autovía León-Valladolid perjudicó a los usuarios de esta ruta de alta utilización. Y no parece que la situación vaya a cambiar, pues las previsiones para León del Plan Regional de Carreteras 2008-2020 van dirigidas fundamentalmente a la modernización de las autovías y accesos a las ciudades y a la mejora de algunas carreteras hasta el momento gestionadas por la Diputación, sin ningún cambio radical en la orientación radial de la planificación.

La modernización de las infraestructuras ferrovíarias ha pivotado sobre las nuevas infraestructuras para acoger la Alta Velocidad, relegando a un segundo plano las líneas convencionales, lo que ha supuesto una profundización también en la jerarquización de la estructura y la priorización del transporte de viajeros sobre el de mercancías. No obstante, la crisis económica que se inició en 2008 ha disminuido drásticamente los recursos disponibles antes de que tales infraestructuras estuvieran terminadas y de que los trenes de Alta Velocidad hubieran llegado a León. En esta situación, el objetivo de las autoridades públicas con respecto al ferrocarril es doble: por un lado conseguir que la Alta Velocidad llegue y atraviese León para poder rentabilizar los recursos que en ella ya se han invertido y, por otro, abordar la modernización necesaria en las líneas convencionales para asegurar la conectividad entre las poblaciones de pequeño (o al menos mediano) tamaño y crear las condiciones necesarias para atraer a las operadoras de transporte y relanzar el uso del ferrocarril para el transporte de mercancías.
La inversión en infraestructuras aéreas parece haber sido un gran fracaso, pues casi quince años después de inaugurado el aeropuerto comercial, varias ampliaciones y millones de euros, la falta de compañías que desean operar en él parece abocarlo al abandono.

Otra de las carencias de la provincia de León que convendría convertir en oportunidad se relaciona con el aprovechamiento de los puertos marítimos más cercanos. El proyecto CyLog contempla la explotación de esta opción para la Comunidad Autónoma y tiene planificados tres puertos secos que se añadirían a los dos ya existentes, pero ninguno de ellos se ubicaría en la provincia de León. Sería altamente recomendable que en el futuro cercano esta situación cambiara para facilitar y aumentar la eficiencia de la logística del tejido empresarial provincial que ya mantiene importantes relaciones con algunos puertos, específicamente el de Gijón-Avilés. También dentro de la Red CyLog, los enclaves de León y Ponferrada deberían recibir los apoyos necesarios, tanto públicos como privados, para asegurar la consecución del objetivo para el que fue creada la red: la prestación de servicios de alta calidad a un precio competitivo proponiendo sistemas logísticos regionales que favorecieran la internacionalización de las empresas.

En cuanto a la prestación de servicios de transporte de mercancías, el número de camiones y furgonetas matriculados en la provincia de León, aunque con altibajos, creció casi un 60\% entre 1986 y 2005, pasando de 1.921 matriculaciones anuales a 3.001. Pero desde entonces, no han hecho otras cosa que reducirse y en 2012 sólo se matricularon 533 vehículos. En este mismo año había en León 3.107 autorizaciones nacionales de servicio público en vehículos pesados repartidas en 1.122 empresas y otras 2.104 autorizaciones para vehículos pesados de servicio privado repartidas en 1.136 empresas. Estos datos indican una mayor atomización del sector empresarial leonés en relación al conjunto de la nación, lo que podría ser indicio de niveles de modernización escasos o de un mayor riesgo de absorción por parte de corporaciones más grandes $y$, por tanto, un aspecto a mejorar en el futuro. 
Los productores leoneses utilizan más el ferrocarril para enviar sus mercancías a otros lugares de lo que lo usan, junto con los consumidores, para recibirlas. Además, la utilización de este modo de transporte ha experimentado una evolución en $U$, al disminuir hasta 1996, para volver a recuperarse durante los 10 años siguientes. En 2007 se transportaron por ferrocarril 1.557 toneladas de mercancías con origen o destino León, pero la crisis también hizo que se redujera drásticamente este volumen que en 2012 apenas alcanzó las736.000 Tn.

En cuanto al transporte de viajeros por carretera, las matriculaciones de autobuses también siguieron una senda creciente desde 1986, año en que se matricularon 16 vehículos, hasta finales de la década de 2000, cuando se matricularon alrededor de 80 autobuses al año. Pero desde 2009 el proceso se ha estancado y en la actualidad, los niveles son similares a los de hace diez años debido, principalmente, a la crisis económica pero también a la competencia que han supuesto los nuevos servicios ferroviarios que unen León con Madrid. Este hecho obligará a las empresas de transporte en autobús a concentrarse en itinerarios alternativos (intraprovinciales, transversales hacia este y oeste...) o en mejorar la relación calidad/precio de los servicios radiales. De otra manera, la importancia relativa de la actividad en León, donde se localizan el $23,4 \%$ de las autorizaciones de servicio público de la Comunidad Autónoma, bajaría.

Efectivamente, la puesta en funcionamiento en 2008 del servicio Alvia con destino Madrid constituyó una reversión radical de la tendencia negativa que estaba sufriendo el transporte de viajeros por ferrocarril como modo de transporte: ese año, el número de viajeros en AVELarga Distancia se incrementó más de un 30\% con respecto al periodo anterior y en 2009 volvió a crecer otro $26 \%$ más. Este hecho evidencia que cuando los servicios ofrecidos son de calidad, el uso del ferrocarril es una inmejorable opción. Las líneas de Cercanías y en menor medida las de Media Distancia, no han experimentado estas mejoras, por lo que están sufriendo una paulatina reducción en su frecuencia y número de paradas, que resulta en la disminución del número de usuarios y en un problema importante para la vertebración del territorio provincial.

En resumen, durante los últimos veinticinco años, tanto las inversiones en la red de carreteras como en la red de ferrocarril han primado la jerarquizada red radial que une la capital de la provincia ( $y$ en menor medida Ponferrada) con Asturias y Madrid, abandonando las conexiones intraprovinciales. Esta priorización ha mejorado la eficiencia en la logística de las empresas situadas a lo largo de estas redes y los servicios de transporte de la población concentrada en las ciudades más grandes de la provincia, pero no ha contribuido a mejorar los servicios públicos prestados a la dispersa población rural ni ha ayudado a la extensión de la actividad empresarial por el territorio rural; es decir, no ha favorecido, sino todo lo contrario, la lucha contra la concentración poblacional que sufre la provincia de León desde hace varios años.

\section{Referencias}

ADIF (Administrador de Infraestructuras Ferroviarias). Sitio web oficial: <http://www.adif.es>.

Bel, G. y García-Milá, T. (2007). Dotación y gestión de infraestructuras de transporte. En A. de la Fuente y T. García-Milà (Eds.), L'Economia catalana: Repte i oportunitats (pp. 269-295). Barcelona: BBVA y Dep. d'Economia i Finances de la Generalitat de Catalunya.

CECALE (Confederación de Organizaciones Empresariales de Castilla y León) (2007). Estudio sectorial sobre la situación y perspectivas en el transporte de mercancías por carreteras de Castilla y León. Prospectiva del Modelo CyLOG. Valladolid.

CES (Consejo Económico y Social de Castilla y León) (2008). Situación económica y social de Castilla y León en 2007. Valladolid. 
Comisión de las Comunidades Europeas (2002). Libro Blanco sobre la política común de transportes. La política europea de transportes de cara al 2010: la hora de la verdad. Luxemburgo: Oficina de Publicaciones Oficiales de las Comunidades Europeas.

De Rus, G. (2009). La medición de la rentabilidad social de las infraestructuras de transporte. Investigaciones Regionales, (14), 187-210.

DGT (Dirección General de Tráfico): Anuario Estadístico General. Varios años. Sitio web oficial: http://www.dgt.es/portal/es/seguridad_vial/estadistica/publicaciones/anuario_general/.

Diputación de León. (2011). Encuesta de infraestructuras y equipamiento local-fase 2010. León: Servicio de Empresa, Conocimiento e Innovación Tecnológica.

EURORAP (European Road Assessment Programme). Sitio web oficial: http://www.eurorap.org.

FEVE (Ferrocarriles de Vía Estrecha). Sitio web oficial: http://www.feve.es.

Fundación CETMO (2006). El transporte de mercancías por carretera, un sector de peso con tres retos estratégicos: Internacionalización, intermodalidad e innovación. Barcelona.

González García, J.L. (IP) (2006). Aplicación del protocolo de Kyoto para Castilla y León. Valladolid: Consejo Económico y Social de Castilla y León.

INE (Instituto Nacional de Estadística) (varios años). Contabilidad regional de España. Sitio web oficial: http://www.ine.es/jaxi/menu.do?L=0\&type=pcaxis\&path=\%2Ft35\%2Fp010 \&file=inebase.

INE (Instituto Nacional de Estadística) (2008). Indicadores de actividad del sector servicios. Base 2005 Diciembre 2007. Madrid: Dirección General de Estadística Sitio web oficial: http://www.ine.es/jaxi/menu.do?type=pcaxis\&path=/t37/p183\&file=inebase\&L=0.

Junta de Castilla y León. Anuario estadístico de Castilla y León. Varios años. Valladolid: Consejería de Economía y Hacienda.

Junta de Castilla y León (2009): Plan Regional Sectorial de Carreteras 2008-2020. Valladolid: Dirección General de Infraestructuras y Carreteras. Consejería de fomento y Medio Ambiente.

Junta de Castilla y León (2011). Plan Regional de Aforos. Memoria 2011. Valladolid: Dirección General de Infraestructuras y Carreteras. Consejería de fomento y Medio Ambiente.

Ministerio de Fomento. Estadísticas. Datos del registro. Sitio web oficial: http://www.fomento.gob.es/ mfom/lang_castellano/direcciones_generales/transporte_por_carretera/_informacion/informacion_e stadistica/datos_registro.htm.

Ministerio de Fomento (2001). Plan estratégico para el sector del transporte de mercancías por carretera (PETRA). Madrid: Dirección General de Transportes por Carretera.

Ministerio de Fomento (2005). Plan Estratégico de Infraestructuras y Transporte (PEIT) 2005-2020. Madrid: S.E. de Infraestructuras y Planificación.

Ministerio de Fomento (2008 y 2012). Observatorio del transporte de viajeros. Madrid: S.E. de Transporte.

Ministerio de Fomento (2012). Plan de Infraestructuras, Transporte y Vivienda (PITVI) 2012-2024. Madrid: S.E. de Infraestructuras, Transporte y Vivienda.

Seguí Pons, J.M. y Martínez Reynes, M.R. (2003). Geografía de los transportes. Palma de Mallorca: Universitat de les Illes Balears. 